University of Louisville ThinkIR: The University of Louisville's Institutional Repository

Electronic Theses and Dissertations

$5-2013$

\title{
Preliminary assessment of a school-based healthy lifestyle program among rural children.
}

Jiying Ling

University of Louisville

Follow this and additional works at: https://ir.library.louisville.edu/etd

\section{Recommended Citation}

Ling, Jiying, "Preliminary assessment of a school-based healthy lifestyle program among rural children." (2013). Electronic Theses and Dissertations. Paper 837.

https://doi.org/10.18297/etd/837

This Master's Thesis is brought to you for free and open access by ThinkIR: The University of Louisville's Institutional Repository. It has been accepted for inclusion in Electronic Theses and Dissertations by an authorized administrator of ThinkIR: The University of Louisville's Institutional Repository. This title appears here courtesy of the author, who has retained all other copyrights. For more information, please contact thinkir@louisville.edu. 
PRELIMINARY ASSESSMENT OF A SCHOOL-BASED HEALTHY LIFESTYLE

PROGRAM AMONG RURAL CHILDREN

\author{
By \\ Jiying Ling \\ BSN, Shandong University, 2008

\begin{abstract}
A Thesis
Submitted to the Faculty of the

School of Public Health and Information Sciences of the University of Louisville in Partial Fulfillment of the Requirements

for the Degree of

Master of Science
\end{abstract} \\ Department of Bioinformatics and Biostatistics \\ University of Louisville \\ Louisville, Kentucky
}

May 2013 
Copyright 2013 by Jiying Ling

All rights reserved 

PRELIMINARY ASSESSMENT OF A SCHOOL-BASED HEALTHY LIFESTYLE PROGRAM AMONG RURAL CHILDREN

\author{
By \\ Jiying Ling \\ BSN, Shandong University, 2008
}

A Thesis Approved on

April 15, 2013

By the following Thesis Committee:

Dongfeng $\mathrm{Wu}$ (Thesis Director), $\mathrm{PhD}$

Kristi King, PhD, CHES

Seongho Kim, PhD 


\section{DEDICATION}

This thesis is dedicated to

my parents who have provided me unconditional love and invaluable support, and my husband, Fujun Wen, who encouraged me to explore. 


\section{ACKNOWLEDGEMENTS}

I would like to thank Dr. Dongfeng $\mathrm{Wu}$, my thesis advisor, for her guidance, support and patience throughout the process. Without her tutelage, my pursuit in the biostatistics area would surely have been inhibited. Not only does she care about my academic development, but also my personal development. All success I have achieved and will achieve in the future regarding academic pursuit will be due to her guidance and advice. I especially thank my committee member, Dr. Kristi King, for her valuable dataset and productive collaboration. Without her, I would never be able to pursue the research area in healthy lifestyle promotion among children. I will regard her as my best friend and best collaborator forever. Thank Dr. Seongho Kim for his guidance and help on data analysis and results interpretation. Thanks to all my committee for a successful and enjoyable defense.

Specifically, I want to thank Dr. Rosalie Mainous for believing in my ability, encouraging me to pursue my interests, and providing me this opportunity to develop. Without her support and encouragement, I would have never thought about pursuing a master degree in biostatistics, and would never have had the confidence to successfully achieve it. The tangible and intangible support from her make my dream come true. I will be forever indebted to her and will forever regard her as my mentor in life. 


\section{ABSTRACT \\ PRELIMINARY ASSESSMENT OF A SCHOOL-BASED HEALTHY LIFESTYLE PROGRAM AMONG RURAL CHILDREN \\ Jiying Ling \\ April 15, 2013}

Introduction: Childhood obesity has become a national public health crisis in America. Physical inactivity and unhealthy eating behavior may contribute to childhood obesity. School-based programs focusing on healthy lifestyles play a promising role in preventing and controlling childhood obesity.

Purpose: To assess the preliminary effects of a school-based program on physical activity and eating behavior among rural children.

Methods: A quasi-experimental study design with repeated measures (intervention group only) was utilized. Children from kindergarten to fifth grade in four rural elementary schools in Kentucky participated in the study. A variety of strategies were implemented to obtain four goals: (1) improving physical activity level, (2) improving health and nutrition education, (3) promoting family/community involvement through Family Fitness Fun Nights, and (4) realigning school's wellness policy with HealthierUS School Challenge. Physical activity was assessed by pedometer logs of step counts ( 4 consecutive days), while fruits and vegetables consumption were assessed by a previous day recall survey. Data were collected in January (baseline), February (t1), 
March (t2), April (t3) and May (t4) of 2010. Repeated measures ANOVA and mixedeffects regression models were used.

Results: A total of 1,508 children, 814 boys and 679 girls (15 missing sex), participated in this study. The program had significant effects on increasing the percentage of children meeting nutrition $(14.8 \%$ vs. $25.9 \%, p<0.01)$ and physical activity recommendations $(1.4 \%$ vs. $5.0 \%, p<0.01)$. There were significant main effects of school, time, sex and grade on physical activity and eating behavior. The effects of the program on physical activity and eating behavior depended on school, grade and age of the children. Children's physical activity level was positively correlated with their grade level. Generally, there was an increasing linear trend of physical activity and an increasing quadratic trend of eating behavior over time.

Conclusions: The school-based healthy lifestyle program had beneficial effects on improving healthy behaviors among children. Further studies are needed to assess the long-term health effects and cost-effectiveness of this program. 


\section{TABLE OF CONTENTS}

PAGE

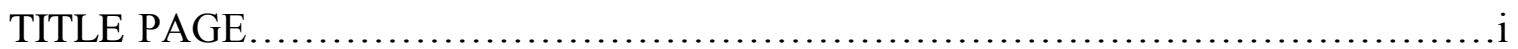

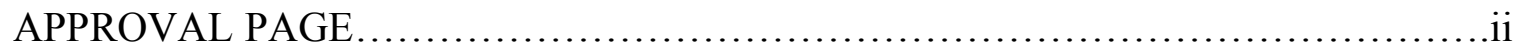

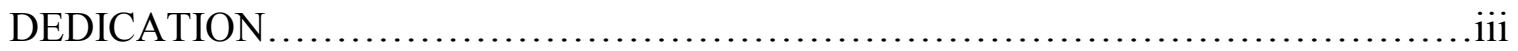

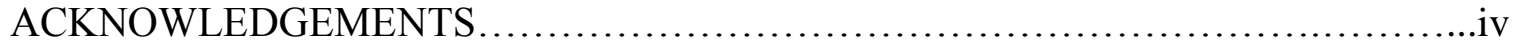

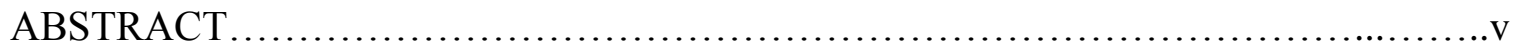

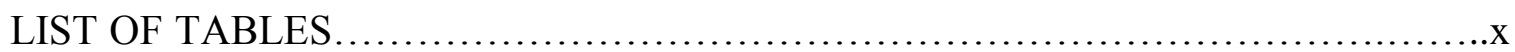

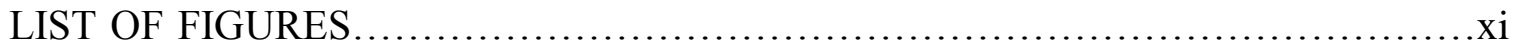

\section{CHPATER 1 INTRODUCTION}

Childhood Obesity ..........................................................

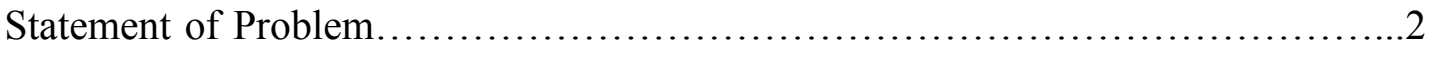

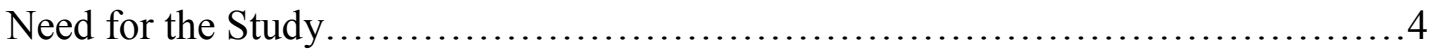

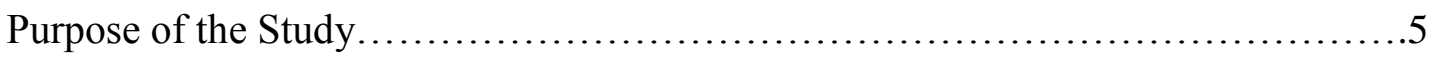

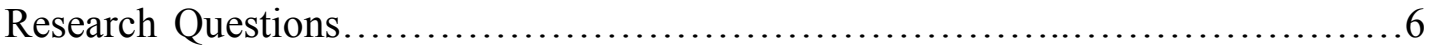

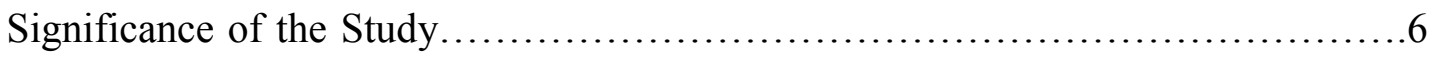

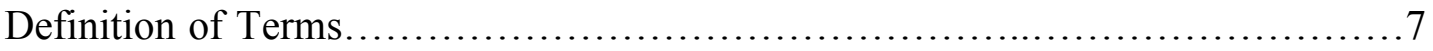

\section{CHAPTER 2 REVIEW OF THE LITERATURE}

Physical Activity......................................................... 13

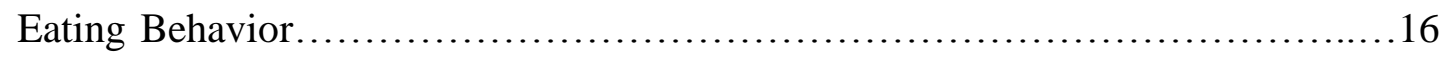

Childhood Obesity Interventions........................................... 18

Statistical Techniques to Evaluate Interventions...............................20 
Rural Residency as a Health Indicator....

Children in Kentucky.....................................................24

Statistical Methods Used in Repeated Measures Design.........................28

\section{CHAPTER 3 METHODOLOGY}

Research Design....................................................... 35

Measurements......................................................... 35

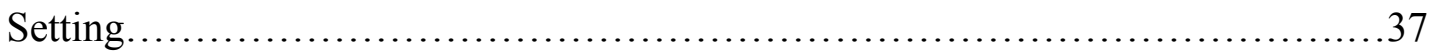

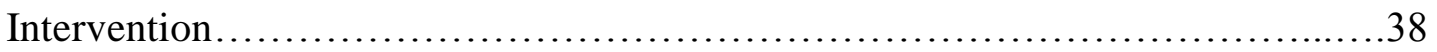

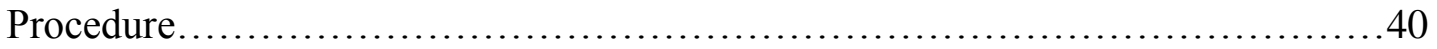

Data Analysis........................................................40

Sample................................................................ 41

\section{CHAPTER 4 RESULTS}

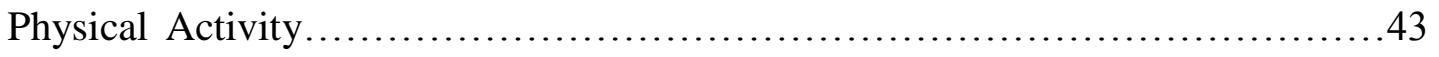

Eating Behavior.....................................................47

Comparison of Statistical Models...........................................54

\section{CHAPTER 5 SUMMARY, DISCUSSION, AND CONCLUSIONS}

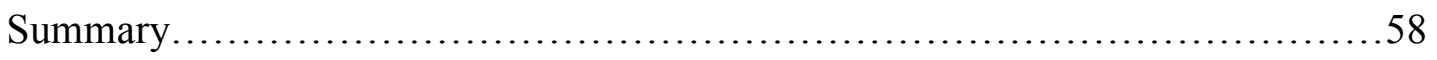

Discussion.........................................................6 60

Limitations.......................................................... 64

Conclusions.........................................................65

REFERENCES ........................................................67

APPENDICES.......................................................... 82

A Pedometer Log Sheet for $k-5^{\text {th }}$ Grade Students............................82 
B Nutrition Survey for K-5 ${ }^{\text {th }}$ Grade Students.............................. 84

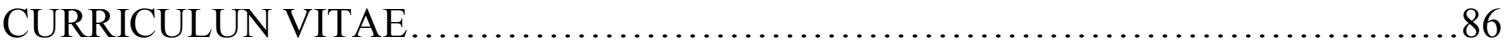




\section{LIST OF TABLES}

$\begin{array}{ll}\text { TABLE } & \text { PAGE }\end{array}$

1. Aims and strategies of the Healthy, Hunger-Free Kids Act of $2010 \ldots \ldots \ldots \ldots \ldots \ldots . . .26$

2. Eight components of a Coordinated School Health program.....................27

3. Analysis of variance for two-factor experimental with repeated measures on time...31

4. Elementary school-based intervention goals, descriptions, and key personnel........39

5. Demographic information of subjects.....................................42

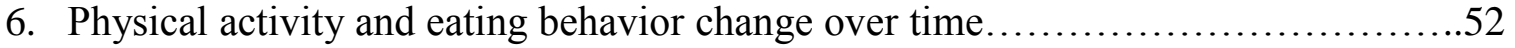

7. Model comparisons (comparing to repeated measures ANOVA using compound

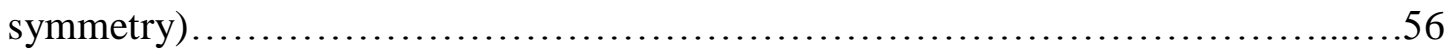




\section{LIST OF FIGURES}

$\begin{array}{lll}\text { FIGURE } & \text { PAGE }\end{array}$

1. Examples for variance-covariance structures................................ 32

2. School-wised trend of children's physical activity level over time................46

3. Trend of children's physical activity level over time based on sex...................46

4. Trend of children's physical activity level over time based on grade level............47

5. School-wised trend of children's eating behavior over time.....................50

6. Trend of children's eating behavior over time based on sex.......................50

7. Trend of children's eating behavior over time based on grade level................51 


\section{CHAPTER 1 \\ INTRODUCTION \\ Childhood Obesity}

Childhood obesity has become a public health crisis in the United States (U.S.), with significant geographic, sex, age and ethnic disparities (Ogden, 2010). Results from the National Health and Nutrition Examination Survey (NHANES) indicate that between 1963 and 2008, childhood obesity rates have tripled, and obesity rates are disproportionately high among children aged 6 to 11 years old (Ogden, 2010). Today, nearly one in three children in the U.S. is overweight or obese (American Heart Association, 2012). In Kentucky, nearly $40 \%$ of children are overweight or obese (Alliance for a Healthier Generation, 2011). Current evidence suggests that the prevalence of childhood obesity is likely to remain on the rise, and it has been estimated that by the year 2030 , more than $60 \%$ of American children and nearly $90 \%$ of American adults will become overweight or obese (Y. Wang, Beydoun, Liang, Caballero, \& Kumanyika, 2008). Obesity has very serious influences on children's health, and it is associated with a range of adverse metabolic and cardiovascular conditions (C. L. Williams et al., 2002), poor self-esteem (F. Wang \& Veugelers, 2008), an increased likelihood of being obese in adulthood (Y. Wang et al., 2008), and increasing health care costs (G. Wang \& Dietz, 2002). Thus, effective programs on preventing and controlling childhood obesity are urgently needed. 


\section{Statement of Problem}

Obesity is a global epidemic and has a rising trend among children (Lobstein, Baur, Uauy, \& Iaso International Obesity TaskForce, 2004). Obesity not only affects children's physical and psychological health, but also influences subsequent adult health as obese children typically remain obese as adults (Reilly et al., 2003).

\section{Short Term Effects}

Short-term effects of childhood obesity can be categorized into psychological and cognitive consequences and the development of cardiovascular risk factors in childhood. Evidence has concluded that obese children are more likely to experience psychological problems than non-obese children (Reilly et al., 2003). Specifically, obese children tend to have lower self-esteem than non-obese children by demonstrating significantly higher rates of sadness, loneliness and nervousness (Strauss, 2000). As a result, obese children are more likely to engage in high-risk behaviors such as smoking or consuming alcohol. In addition, obese children tend to have lower visuospatial organization, that is, the visual perception of spatial relationships among objects, and lower general mental ability, compared to normal-weight children (Li, Dai, Jackson, \& Zhang, 2008).

A literature review concluded that childhood overweight and obesity was significantly associated with poorer academic performance (Taras \& Potts-Datema, 2005). However, some researchers suggest that obesity is only a marker instead of a causal factor of poorer academic performance. In other words, childhood obesity is significantly correlated with poorer academic performance, but not significantly correlated with poorer academic performance after controlling socioeconomic status and parents' education level (Datar, Sturm, \& Magnabosco, 2004; Judge \& Jahns, 2007; 
Veldwijk et al., 2012). Further researches are needed to clarify the relationship between childhood obesity and academic performance.

Results from previous studies have consistently supported that childhood obesity is correlated with cardiovascular risk factors - hypertension, dyslipidemia, abnormalities in left ventricular mass and/or function, abnormalities in endothelial function, and hyperinsulinemia/insulin resistance (Reilly, 2005). Expert committee reports and reviews have recommended that childhood obesity should be considered as an important component of cardiovascular risk (C. L. Williams et al., 2002).

\section{Long Term Effects}

Childhood obesity not only has short-term effects, but also has long-term effects as the current generation of obese children becomes adults. It has been estimated that two in three children born after 2000 will suffer from obesity-related health problems such as cardiovascular disease, diabetes, hypertension, cancer, gall bladder disease, osteoarthritis, endocrine disorders and asthma at some point in their life (Lobstein et al., 2004). Evidence indicates that more than $70 \%$ of obese children will become obese adults (Reilly et al., 2003). As a result of the persistence of obesity, the current American generation might have a shorter life expectancy than their parents (Olshansky et al., 2005).

The economic costs of childhood obesity are especially evident in health care expenditures (G. Wang \& Dietz, 2002; Y. Wang et al., 2008). Obesity-associated annual hospital costs increased from $\$ 35$ million during 1979-1981 to \$127 million during 19971999 (G. Wang \& Dietz, 2002). The direct health care costs of childhood obesity include $\$ 14.1$ billion of prescription drug, emergency room and outpatient costs, and \$237.6 
million of inpatient costs per year (Trasande \& Chatterjee, 2009; Trasande, Liu, Fryer, \& Weitzman, 2009). Much larger costs are incurred when obese children become obese adults. In 2011, the health care costs of obesity-related diseases among adults were estimated at approximately $\$ 147$ billion per year, and by 2030 , the health care costs attributed to overweight and obesity are projected to account for $\$ 900$ billion per year, or for one in every 6 dollars spent on health care (Y. Wang et al., 2008). In addition, adult obesity accounts for about $\$ 4.3$ billion related to job absenteeism per year (Cawley, Rizzo, \& Haas, 2007), and $\$ 506$ of losses related to low work productivity per obese worker per year (Gates, Succop, Brehm, Gillespie, \& Sommers, 2008). Thus, costeffective childhood obesity prevention and intervention programs are urgently needed for the nations' financial health.

\section{Need for the Study}

Considering the magnitude of childhood obesity epidemic and its great health and economic effects, cost-effective interventions or programs are urgently needed. Evidence has supported that unhealthy behaviors - physical inactivity and unhealthy eating - are significantly correlated with the childhood obesity epidemic (Slyper, 2004). However, the majority of American children do not meet the recommendations for physical activity and nutrition (Bock \& Miller, 2008; Slyper, 2004). Furthermore, the overall decline in fitness and nutrition levels lead to the inescapable conclusion: American children need more physical activity, along with knowledge of health, wellness, nutrition and physical activity (Center for the Advancement of Physical Education, 2004; Rowland, 2007). Both family-based and school-based healthy lifestyle programs have shown significant effects on reducing weight and sedentary activity, and increasing physical activity (Bacardi- 
Gascon, Perez-Morales, \& Jimenez-Cruz, 2012; Greening, Harrell, Low, \& Fielder, 2011; Sacher et al., 2010). School-based healthy lifestyle programs are cost-effective, and schools are considered an ideal setting for healthy lifestyle promotion programs (BacardiGascon et al., 2012; H. S. Brown et al., 2007). Further, evidence indicates that children in rural areas are more likely to be overweight or obese, and participate in unhealthy behaviors (Liu, Bennett, Harun, \& Probst, 2008; Liu et al., 2010). Childhood is a crucial time when healthy behaviors are learned and adopted, and early childhood intervention programs can make a significant difference to a child's life changes (Gray \& Francis, 2007). Therefore, comprehensive school-based programs have a promising role in promoting healthy lifestyle and preventing or controlling obesity among children, especially children in rural areas.

\section{Purpose of the Study}

The purpose of this study was to assess the preliminary effects of a comprehensive school-based program on physical activity and healthy eating behavior using multiple-sample repeated measures ANOVA and mixed-effects regression models among children from kindergarten to fifth grade in four rural elementary schools in Kentucky. The overall aims of the intervention are to increase children's daily physical activity, improve children's cardiorespiratory fitness, and improve children's nutrition habits. The school-based healthy lifestyle intervention was developed based on the principles of the Coordinated School Health Program recommended by Centers for Disease Control and Prevention (CDC) (2011c). The intervention included four goals: (1) improving physical activity level, (2) improving health and nutrition education (U.S. Department of Health and Human Services, 2012), (3) promoting family/community 
involvement through Family Fitness Fun Nights, and (4) realigning school's wellness policy with HealthierUS School Challenge (U.S. Department of Agriculture, 2011b). For purposes of this study, children's physical activity level and eating behavior were assessed over the course of the first year of the program.

\section{Research Questions}

1. How did sex, school and grade influence the effects of the program on physical activity level over time among children?

2. How did sex, school and grade influence the effects of the program on eating behavior over time among children?

3. Which statistical method is more efficient used in repeated measures design?

\section{Significance of the Study}

This study found that the comprehensive school-based healthy lifestyle program had significant effects on promoting healthy behaviors - physical activity and healthy eating - among children. Future researchers or policy makers could adopt and popularize this program to other rural elementary schools throughout the U.S. to improve children's health and lower health care costs related to childhood obesity. In addition, future studies can learn valuable lessons through assessing the design, procedure and evaluation methods in this study. Though this program is school-based, it also involves parents and community through hosting Family Fitness Fun Nights. The design of this program also

emphasizes the important role of school health policy in promoting healthy behaviors and controlling childhood obesity.

Findings from this study could make significant contributions on designing healthy lifestyle programs and improving American's health from one generation to 
another. This study recommends that healthy lifestyle promotion programs should focus on lifelong, habit-forming behaviors of physical activity and healthy eating, because healthy habits can be maintained throughout life from one generation to another. However, further studies are still needed to evaluate its cost effectiveness and effects on controlling childhood obesity.

This study emphasizes the significance of using mixed-effects regression models in analyzing repeated measures data. Mixed-effects regression models are robust to the assumption of sphericity, and can fit different covariance patterns leading more appropriate fixed effects estimates (H. Brown \& Prescott, 2006). Results from this study indicates that the two most promising variance-covariance structures were unstructured and autoregressive heterogeneous variances, which did not meet the assumption of sphericity. In other words, multiple-sample repeated measures ANOVA was not suitable in analyzing the data. Moreover, mixed-effects regression models can deal with missing data easily without deleting cases with missing data, and they can be applied to the repeated measures data with unequal time intervals.

\section{Definition of Terms}

To clarify the meaning of the concepts, the following definitions were used in this study.

Body Mass Index (BMI): Child's BMI is a number calculated from weight and height using the formula 'BMI $=($ Weight in Kilograms $/($ Height in Meters $\times$ Height in Meters))'. For children, BMI is age- and sex-specific, and is often referred as BMI-forage. BMI cannot directly measure body fat, but it has been supported to be a reliable indicator of body fatness for most children. After obtaining BMI, the number is plotted 
on a CDC BMI-for-age chart to obtain a percentile ranking. The BMI percentile is an indicator to assess the size and growth patterns of individual child in the U.S. (CDC, 2011a).

Child and Adolescent: A child is defined as a person aged 4 to 11 years old, and an adolescent is defined as a person aged 12 to 19 years old (CDC, 2011b). For this study, all participants will be referred to as children, although some were adolescents.

Overweight: Childhood overweight is defined as a BMI at or above the 85th percentile and lower than the 95th percentile for children of the same age and sex (CDC, 2011f).

Obesity: Childhood obesity is defined as a BMI at or above the 95th percentile for children of the same age and sex (CDC, 2011f).

Physical Activity: Physical activity refers to "any bodily movement produced by skeletal muscles that results in energy expenditure" (Caspersen, Powell, \& Christenson, 1985, p. 126). Generally, physical activity has four elements: (1) bodily movement produced by skeletal muscles, (2) results in energy expenditure, (3) energy expenditure varies continuously from low to high, and (4) positive correlation with physical fitness (Caspersen et al., 1985).

Exercise: Exercise is physical activity that is planned, structured, repetitive, and purposive to improve or maintain some component of physical fitness (Caspersen et al., 1985). Exercise is one subset of physical activity, that is, physical activity includes exercise.

Physical Fitness: Physical fitness is a set of attributes that people have or achieve that relate to the ability to perform movement. Physical fitness has five components: 
cardiorespiratory, body composition, muscular strength, muscular endurance, and flexibility (Caspersen et al., 1985).

Fruit and Vegetable: Both fruits and vegetables - when prepared without adding solid fats or sugars - are nutrient-dense foods, which provide vitamins, minerals, and other substances that have positive health effects with relatively low calorie. Nutrientdense refers to the nutrients or other beneficial substances that have not been diluted by the addition of calories from solid fat, sugar, or other added refined starches (U.S. Department of Agriculture, 2011a).

Categorical Variable: Categorical variable has a measurement scale consisting of a set of categories and it has two primary types of scales, nominal and ordinal. Nominal variables refer to the variables that have categories without a natural ordering, while ordinal variables are variables that have ordered categories. Though ordinal variables have ordered categories, distances between categories are unknown (Agresti, 2007).

Numerical Variable: Numerical variable refers to a variable that has a numeric value and it can be divided into two categories, interval and ratio. Both interval variables and ratio variables have equal intervals between two values and absolute zero is the only difference between these two kinds of variables. An interval variable does not have absolute zero while a ratio variable has absolute zero (Kutner, Nachtsheim, Neter, \& Li, 2005).

Two-Independent-Samples $t$ test: Two-independent-samples $t$ test is a test to compare the mean scores of two groups on a dependent variable. The assumptions for using this method are: (1) the distribution of the sample means is normally distributed; and (2) the two groups are independent from each other. Based on the Central Limit 
Theorem, if the sample size is $\geq 30$, then the distribution of the sample means will be normally distributed approximately (Norusis, 2010).

\section{One-Way Analysis of Variance (ANOVA): One-Way ANOVA is a test to} compare the means of two or more groups on a dependent variable. The assumptions for using this method are: (1) the distribution of the sample means is normally distributed; (2) the two or more groups have approximately equal variances on the dependent variable, which can be assessed by Levene's or Bartlett's Tests; and (3) the two or more groups are independent from each other. Based on the Central Limit Theorem, if the sample size is $\geq 30$, then the distribution of the sample means will be normally distributed approximately (Norusis, 2010).

Cochran-Mantel-Haenszel Test: Cochran-Mantel-Haenszel test is a test to examine the independence of repeated tests for ordinal variables and it is analogous to a two-way ANOVA for a measurement variable. The Cochran-Mantel-Haenszel test potentially removes the confounding influences of the explanatory variables that comprise the stratification and can provide increased power for detecting associations by comparing similar subjects (Stokes, Davis, \& Koch, 2000).

Simple Linear Regression: Simple linear regression is a statistical technique to assess the effects of an independent variable $X$ on a dependent variable $Y$. The assumptions for using this test are: (1) all $Y$ values are independent of each other; (2) the values of $Y$ follow normal distribution for each $X$ value; (3) there is a linear relationship between $X$ and $Y$; and (4) the standard deviation of $Y$ at any given value of $X$ is the same. The linear model can be expressed by $Y_{i}=\alpha+\beta X_{i}+\varepsilon_{i}$. The parameters $\alpha$ and $\beta$ are called regression coefficients. The parameter $\alpha$ is the intercept of the regression model, 
that is, $\alpha$ gives the mean of the probability distribution of $Y$ when $X=0$. The parameter $\beta$ is the slope of the regression line, which indicates the change in the mean of the probability distribution of $Y$ per unit increase in $X . \varepsilon_{i}$ is the random error with mean 0 and variance $\sigma^{2}$ (Kutner et al., 2005).

Univariate Repeated Measures ANOVA: Univariate repeated measures ANOVA, as an extension of paired t-test, is used to test the equality of means when a dependent variable is measured under a number of different conditions. Three assumptions should be held to use the repeated measures ANOVA: (1) the observations are independent; (2) multivariate normality, that is, each individual variable is normally distributed with respect to each other variable, which can be assess by Mardia's tests of multivariate Skewness and Kurtosis, or multivariate Shapiro-Wilk test; and (3) Sphericity, that is, the homogeneous of variance, assessed by the Mauchly's test (Stevens, 2009). A principal advantage of univariate repeated measures ANOVA is that the variations between subjects are excluded from the experimental error, and only variations within subjects are included in the experimental error (Kutner et al., 2005). In this study, multiple-sample repeated measures ANOVA was used to test the effects of intervention (time effect) within-subject effects, factor A (a demographic variable) - between-subject effects, and interaction effects between intervention and Factor A on healthy behaviors.

Mixed-Effects Regression Models: Mixed-effects regression models can be used in the repeated measures design. Compared to univariate repeated measures ANOVA, they have three advantages: (1) it can handle missing data easily; (2) the time interval can be unequal among subjects; and (3) it is robust to the assumption of sphericity (Howell, 2010). In a mixed-effects regression model, it has both fixed effects and random effects. 
Through adding random effects in the model, we assume that subjects differ on average, or the random effects have different influences on each individual. If the research purpose is to infer the general change patterns of a dependent variable, it is suggested that the time should be considered as a random factor (Blackwell, de Leon, \& Miller, 2006).

Main Effect: Main effect is the overall effects of one independent variable on a dependent variable, while ignoring the effects of all other independent variables (Stevens, 2009).

Interaction Effect: Interaction effect is that the effects of one independent variable on a dependent variable depend on another independent variable (Stevens, 2009). 


\section{CHAPTER 2}

\section{REVIEW OF THE LITERATURE}

This chapter presents a review of literature related to the physical activity levels and eating behaviors among children, childhood obesity interventions, and statistical methods used to evaluate interventions. Further, rural residency as a health indicator and policy/programs in controlling childhood obesity in Kentucky will be addressed. Finally, the two commonly used statistical methods, multiple-sample repeated measures ANOVA and mixed-effects regression models, in repeated measures design studies are discussed.

\section{Physical Activity}

\section{Correlation with Childhood Obesity}

Weight is gained when energy intake exceeds energy expenditure. In order to maintain a stable weight, a delicate balance between energy intake and energy expenditure is required. Generally, energy expenditure comprises three components: resting energy expenditure, the thermic effects of food (the energy expenditure in consuming and processing food), and the thermic effects of physical activity. Except the three components of energy expenditure, children need additional energy for growth. The requirement energy need for growth is about 1-2\% of total energy expenditure in

childhood (Steinbeck, 2001). The resting energy expenditure is the minimum energy need to sustain life, and remains relatively constant within individuals over time (Goran \& Treuth, 2001). The thermic effects of food are primary influenced by the composition of 
food, and are relatively stable within individuals over time (Steinbeck, 2001). The thermic effects of physical activity are the most variable component of energy expenditure, and vary within and between individuals due to the variable nature of physical activity (Goran \& Treuth, 2001). Thus, physical activity is the discretionary component of energy expenditure, and lack of physical activity is the most significant contributor to childhood obesity (Hills, Andersen, \& Byrne, 2011; Janssen et al., 2005). Physical activity can increase energy expenditure through its influences on body composition (includes body fat and lean body mass) and metabolism. Moreover, it can increase the capacity to mobilize and burn body fat while using muscles through increasing and maintaining lean body mass (LBM) (Nowicka \& Flodmark, 2007).

Consistent evidence has shown that overweight or obese children participate in lower levels of physical activity compared to normal weight children (Hills et al., 2011; Nowicka \& Flodmark, 2007), and children with higher levels of physical activity have reduced skinfold thickness, while obese children participate in higher levels of sedentary behaviors (Davis et al., 2007; Hills, King, \& Armstrong, 2007). In addition, the 20012002 Health Behavior Survey among 137,593 school-age children from 34 countries reported that greater physical activity participation was significantly correlated with lower odds of overweight in 29 out of 34 countries, including the U.S. (Janssen et al., 2005). Similarly, a study among 1,204 children and adolescents indicated that physical inactivity and sedentary lifestyles were significant determinants of elevated BMI and risk factors contributing to childhood overweight and obesity (Bukara-Radujkovic \& Zdravkovic, 2009). 


\section{Physical Activity Level}

The CDC (2011d) and the U.S. Department of Health and Human Services (2012) recommend that children should participate in at least 60 minutes or more physical activity per day. Specifically, children should participate in several bouts of intermittent moderate to vigorous-intensity physical activity daily, as well as muscle-strengthening and bone-strengthening physical activity at least 3 days a week (U.S. Department of Health and Human Services, 2012).

The Third National Health and Nutrition Examination Survey (NHANES) from 1988 to 1994 found that $44.1 \%$ of boys and $38.4 \%$ of girls aged $8-10$ years old, and $53.1 \%$ of boys and $43.8 \%$ of girls aged $11-13$ years old participated in physical activity for more than 5 days a week (Crespo et al., 2001). However, in 2002, the Youth Media Campaign (YMC) conducted a survey among children aged 9-13 years old, and the results indicated that $61.5 \%$ of children did not engage in any organized physical activity during their non-school hours and $22.6 \%$ of children did not participate in any free-time physical activity (Duke \& Huhman, 2003). The 2003-2004 NHANES found that on average boys and girls performed 45 and 26 minutes of moderate- or vigorous-intensity physical activity per day and about $48 \%$ of boys and $35 \%$ of girls participated in at least 60 minutes physical activity daily (Troiano et al., 2008). Furthermore, boys and girls watched a daily average of 137 and 128 minutes of television (TV) respectively, and approximately $30 \%$ of boys and $25 \%$ of girls watch 4 hours or more TV per day (Marshall, Gorely, \& Biddle, 2006).

Physical activity levels among American children have dropped sharply between age 9 and age 15, and most of the children did not meet the daily recommended physical 
activity level (Bock \& Miller, 2008). At age 9, children participated on average three hours of moderate- or vigorous-intensity physical activity on weekdays and weekends, but by age 15, they only participated on average 49 minutes per weekday, and 35 minutes per weekend (Bock \& Miller, 2008). Additionally, in 2006, more than $69 \%$ of elementary schools, $84 \%$ of middles schools, and $95 \%$ of high schools were required to have physical education. However, only $4 \%$ of elementary schools, $8 \%$ of middle schools, and $3 \%$ of high schools had provided daily physical education to students (Lee, Burgeson, Fulton, \& Spain, 2007). During 1991-1995, there was a significant decline in daily physical education and no change observed during 1995-2003 in high school students, which resulted in the failed achievement of national health objectives (CDC, 2004).

\section{Eating Behavior}

\section{Association to Childhood Obesity}

In addition to physical inactivity, diets with high calories, high sugar, and low fiber have been reported to contribute to childhood obesity (Wieting, 2008). Crosssectional studies have found that children who consumed fast food meals have higher energy intake than children who did not consume fast food (Paeratakul, Ferdinand, Champagne, Ryan, \& Bray, 2003). Moreover, a longitudinal study indicated that for 8 to 12-year-old girls consuming fast food two or more times a week at baseline, $96 \%$ of the girls had larger weight gain at a three-year follow-up compared to girls who did not consume fast food (Thompson et al., 2004). In addition, children consuming fast food consumed more fat, carbohydrate, sugars, while less fibers, milk, and fewer fruits and vegetables than children not consuming fast food (Bowman, Gortmaker, Ebbeling, Pereira, \& Ludwig, 2004). 
Similarly, a longitudinal study among 70 children reported that the mean fat intake recorded between the ages of 2 and 8 years was significantly positive predictor of BMI at 8 years old (Skinner, Bounds, Carruth, Morris, \& Ziegler, 2004). Pediatric experts suggest that an increase in the dietary carbohydrate may be the most important contributor to the childhood obesity epidemic (Slyper, 2004). Evidence strongly supports that sweet beverage consumption is positively correlated with BMI and obesity incidences among children (Ludwig, Peterson, \& Gortmaker, 2001). Furthermore, increased portion sizes have also been reported to contribute to the increasing prevalence of childhood obesity through promoting excessive energy intake. When presented with portions that were twice as big as the age-appropriate standard size, children would consume $25 \%$ more meals and $15 \%$ more calories at lunch (Orlet, Rolls, \& Birch, 2003).

In addition, lower intakes of calcium from milk, cheese, and yogurt are associated with childhood obesity. A longitudinal study among 52 children found that dietary calcium intakes between 2 months and 8 years old were negatively correlated with percentage of body fat at 8 years old (Skinner, Bounds, Carruth, \& Ziegler, 2003). In addition, evidence has supported that fruits and vegetables can protect against increased adiposity in children. Fruits and vegetables have been recommended for obesity prevention/intervention due to their low energy density, high fiber content, and satiety value (Davis et al., 2007).

\section{Eating Behavior}

The U.S. Department of Agriculture (2011b) suggests that children should consume three or more servings of vegetables and two or more servings of fruits per day. In 2004 , only $21 \%$ of children had the recommended five or more servings of fruits and 
vegetables each day. Interestingly, nearly half of all of their vegetable servings were fried potatoes (e.g. French fries or potato chips). From the early to mid-1990s, soda consumption increased dramatically while milk consumption declined dramatically among children (Slyper, 2004). Children as young as seven months old started to consume soda, and about $40 \%$ of children consumed three or more eight-ounce servings of soda per day. In 1977-78, children drank 4 times as much milk as sugar sweetened beverages, but that has decreased to 1.5 times as much milk as sugar sweetened beverages in 1990s. From 1965 to 1996, milk consumption in America declined by 36\% because the saturated fat content of dairy food has placed milk a suspect food (e.g. the negative perception of a food), that is, milk was the top one source of saturated fat (24\%) for children at that time (Slyper, 2004). Currently, more than 33\% of children consume fast food daily (U.S. Department of Health \& Human Services, 2012). Carbohydrate intake has increased because of the decrease in dietary fat. Between 1989 and 1991, the top ten categories of carbohydrate for children were yeast bread (13\% carbohydrate), sodas $(8.5 \%)$, milk (7.9\%), ready-to-eat cereals $(7.4 \%)$, cookies $(7.2 \%)$, sugars $(6.0 \%)$, fruit drinks (4.3\%), pasta (3.9\%), white potatoes (3.7\%), and orange/grapefruit juice (2.9\%) (Subar, Krebs-Smith, Cook, \& Kahle, 1998).

\section{Childhood Obesity Interventions}

The lack of physical activity combined with unhealthy diets has broken the energy balance equation in children. Diets with high calorie, high sugar, and low fiber increase energy intake greatly, while the lack of physical activity decreases energy expenditure. Thus, both physical inactivity and unhealthy diets contribute to the current childhood obesity epidemic. Interventions of childhood obesity focusing on healthy lifestyles can be 
summarized into two categories: family-based and school-based interventions. Both family-based and school-based interventions have shown significant contributions to childhood BMI reduction.

One randomized controlled trial of a family-based community intervention found that children in the intervention group showed beneficial changes in waist circumference, BMI, heart rate, physical activity, sedentary activity, and self-esteem compared to children in the control group after 6 months of intervention (Sacher et al., 2010). In addition, evidence supported that family-based interventions had long-term effects on children's BMI, physical activity, sedentary activity, blood pressure, and diet, and the influence patterns were similar between boys and girls (Brotman et al., 2012).

Since children spend most of their daytime in school, this setting has been considered an ideal site for healthy lifestyle promotion programs (Bacardi-Gascon et al., 2012). A randomized cluster controlled trial indicated that a six-month, school-based intervention had significant effects on decreasing abdominal obesity, sedentary activity, snacks consumption, and increasing vegetable consumption and physical activity (Bacardi-Gascon et al., 2012). Similarly, another eight-month, school-based, healthy lifestyles intervention in a rural community found that schools in the intervention group showed significant changes in percentage of body fat, physical activity, physical fitness, and eating habits compared to schools in the control group. However, the effects of the program were not significantly different based on sex or ethnicity (Greening et al., 2011). Thus, both family-based and school-based childhood healthy lifestyles interventions have effects on controlling obesity, and promoting healthy behaviors, but the influence patterns are not different between boys and girls. 
Pediatric experts have recommended four primary behavioral strategies for weight management: (1) reduce energy intake while maintaining optimal nutrition intake; (2) increase energy expenditure through promoting more physical activity and less sedentary activity; (3) engage family as agents of change; and (4) facilitate a supportive family environment (Kirk, Scott, \& Daniels, 2005). Childhood obesity programs promoting lifestyle changes showed reductions in percent overweight of $8.2 \%$ during treatment and 8.9\% at follow-up (Kelly \& Kirschenbaum, 2011).

Evidence also shows strong public support for interventions aimed at controlling overweight and obesity among children. The majority of Americans favored school-based interventions, such as teaching students healthy eating and exercise habits in school; requiring more physical education classes, recess, and supervised intramural activities; restricting unhealthy foods and drinks in school vending machines and school cafeterias; and providing exercise programs for obese children (Evans, Finkelstein, Kamerow, \& Renaud, 2005). In addition, a comprehensive intervention in elementary schools including a classroom curriculum, a physical education program, modifications to the school food services and family-based programs, is supported to be highly cost-effective compared to other programs among adolescents or adults (H. S. Brown et al., 2007; Cawley, 2010). Therefore, comprehensive school-based programs have a promising role in preventing and controlling childhood obesity.

\section{Statistical Techniques to Evaluate Interventions}

Concerning the childhood obesity epidemic, many programs have been designed and conducted to promote children's healthy behaviors and control childhood obesity. This section focuses on the statistical techniques used to assess the effects and cost- 
effectiveness of childhood obesity prevention/intervention programs on healthy behaviors and weight loss.

\section{Effects of Interventions}

For the majority of the studies, outcomes were assessed twice (pretest and posttest) (Greening et al., 2011; Sacher et al., 2010; Siegrist, Hanssen, Lammel, Haller, \& Halle, 2011). IBM SPSS Statistics were the most popular software used in the previous studies. Independent t-test, paired t-test, Mann-Whitney test, chi-square test, and ANOVA were the mostly used statistical techniques to assess the outcome differences between control group and intervention group in pretest and posttest, or to evaluate the intervention effects from pretest to posttest (Bacardi-Gascon et al., 2012; Greening et al., 2011; Sacher et al., 2010; Siegrist et al., 2011). One-way or two-way repeated measures (pretest vs. posttest) MANOVA were used to assess the main effects of intervention and conditions, and the interaction effects of conditions and time (West, Sanders, Cleghorn, \& Davies, 2010). In addition, linear (simple or multiple) and logistic regression have been applied to model the changing patterns of outcomes over time (Brotman et al., 2012; Plachta-Danielzik, Landsberg, Lange, Seiberl, \& Muller, 2011). Blackwell and colleagues (2006) suggested that mixed-effects regression models provide a more flexible and accurate framework for managing repeated measures data compared to conventional statistical techniques, such as, t-test, ANOVA, repeated measures ANOVA/MANOVA, and linear regression et al. For many longitudinal studies, data collected for each subject is correlated over time. Mixed-effects regression models describe complex covariate effects in each subject, while allowing for unexplained population heterogeneity and serial or spatial correlation among repeated measurements (Pedan, n.d.). However, no 
study in behavioral science has been identified to use this statistical method to assess the effects of healthy lifestyle programs.

\section{Cost-Effectiveness of Interventions}

In a world of limited resources for healthy behavior promotion and public health, the healthy lifestyle programs should not just be effective, but also be cost-effective. In 2003, Wang and colleagues first introduced an economic evaluation technique for assessing the cost-effectiveness of childhood obesity prevention programs. This societal method used standard cost-effectiveness and cost-benefit analysis methods to assess the costs and benefits of a program compared to a control program (no intervention). The benefits of a program were measured as quality-adjusted life years (QALYs) and averted costs, that is, the medical costs and productivity costs associated with cases of adulthood overweight prevented (L. Y. Wang et al., 2003). The cost-effectiveness of the program was assessed by the cost-effectiveness ratio (CER) (CER $=$ program costs $/$ QALYS $_{\text {s }}$.

The cost-benefit of the program was assessed by net benefits (net benefits $=$ averted costs - program costs) (L. Y. Wang et al., 2003). This societal method has been widely used to assess the cost-effectiveness of school-based healthy lifestyle programs (H. S. Brown et al., 2007; McAuley et al., 2010).

To perform the economic evaluations, researchers need to be aware of the six steps: (1) retrospective estimation of the program costs; (2) mathematical modeling to transform observed overweight reduction at the current age of children into an estimate of the number of overweight cases prevented in adulthood after age 40 years; (3) estimation of the medical costs averted per case of adulthood overweight prevented; (4) estimation of the number of QALYs saved per case of adulthood overweight prevented; (5) 
estimation of productivity costs averted per case of adulthood overweight prevented; and (6) calculate the CER and the net benefits of the program (Ganz, 2003; L. Y. Wang et al., 2003). However, limitations still exist in the societal method: small sample size, estimation bias, and ignorance of the monetary values of health outcomes, et al (Dalziel \& Segal, 2006). Thus, quality evaluation methods of the cost-effectiveness of programs are urgently needed to provide valuable information for decision-makers and future research activities.

\section{Rural Residency as a Health Indicator}

Nearly $20 \%$ of the U.S. population resides in non-metropolitan areas and are not immune to many health challenges (Bellamy, Bolin, \& Gamm, 2011). Compared to urban children, the majority of rural children is white, poor, and has less-educated parents. Only $22 \%$ of overweighed or obese rural children live in a household with annual family income $>200 \%$ of the federal poverty level compared to $32 \%$ of metropolitan children (Lutfiyya, Lipsky, Wisdom-Behounek, \& Inpanbutr-Martinkus, 2007). Evidence supports that overweight or obese school age children are more likely to live in a rural area rather than a metropolitan area (Liu et al., 2008; Lutfiyya et al., 2007). Consistently, rural children are more likely to be overweight or obese compared to urban children after controlling the socio-demographic characteristics, health and obesity-related behavioral factors. This significant difference is found both in boys and girls (Liu et al., 2010).

Although it would be tempting to assume that rural children might have more opportunities to participate in physical activity and eat healthy food due to the more outdoor spaces and more access to the fresh foods, this is not the case (Cherry, Huggins, \& Gilmore, 2007). Studies revealed that rural children aged 6 to 11 years old consumed 
more fat and tended to have more sugar in their diets than urban children (Cherry et al., 2007; Liu et al., 2010). Overweight or obese rural children are reported to watch TV for more than 3 hours a day and use a computer for non-school work more often than overweight or obese urban children. Moreover, about $41 \%$ of rural children do not participate in any after school activities (Lutfiyya et al., 2007). The difference in prevalence of overweight and obesity might be attributed to the higher prevalence of unhealthy behaviors among rural children. Therefore, rural residency is a risk factor for children being overweight or obese. The higher prevalence of overweight or obesity and unhealthy behaviors (sedentary behaviors and sugar/fat consumption) calls for further research on effective intervention programs among rural children.

\section{Children in Kentucky}

\section{Physical Activity and Nutrition}

In Kentucky, about $61 \%$ of adolescents participated in physical activity at least 60 minutes per day, but fewer than 5 days per week, $29 \%$ watched television three or more hours per day, and $17 \%$ did not participate in at least 60 minutes of physical activity on any day (CDC, 2010). Additionally, 86\% of adolescents consumed fruits and vegetables less than five times per day, $89 \%$ consumed vegetables less than three times per day, $19 \%$ did not eat fruits, and $88 \%$ drank less than three glasses of milk per day (CDC, 2010). It is recommended that children should consume three or more servings of vegetables and two or more servings of fruits (U.S. Department of Agriculture, 2011a), and participate in 60 minutes or more of moderate- or vigorous-intensity physical activity per day (U.S. Department of Health and Human Services, 2012). Accordingly, the majority of Kentuckian children did not meet the recommendations for fruits, vegetables and physical 
activity. Therefore, physical activity and nutrition interventions are urgently demanded for Kentuckian children, especially in low-socioeconomic, rural children, who have been reported to have higher risks of unhealthy behaviors and obesity (Chen \& Matthews, 2002).

\section{Policy and Programs}

Healthy, Hunger-Free Kids Act of 2010. On December 13, 2010, President Obama signed S. 3307, the Healthy, Hunger-Free Kids Act of 2010 into law (The White House: Office of the Press Secretary, 2010). This act aims to authorize funding for federal school meal plan and child nutrition programs and increase access to healthy food for low-income children. Moreover, it reauthorizes child nutrition programs for five years, including $\$ 4.5$ billion new funding for over 10 years. Table 1 describes the specific aims and strategies the act will adopt. The U.S. Department of Agriculture (USDA) has released a chart detailing the implementation timelines for this law (School Nutrition Association, 2011). 


\section{Table 1}

Aims and strategies of the Healthy, Hunger-Free Kids Act of 2010

\begin{tabular}{|c|c|}
\hline Aim & Strategy \\
\hline $\begin{array}{l}\text { Improve } \\
\text { nutrition }\end{array}$ & $\begin{array}{l}\text { (a) set nutritional standards, (b) provide funding to schools, (c) help } \\
\text { communities establish local farms to school networks, (d) improve } \\
\text { nutritional quality of foods, (e) increase access to drinking water in schools, } \\
\text { (f) set standards for school wellness policies while permitting local } \\
\text { flexibility to tailor the policies, (g) promote nutrition and wellness in child } \\
\text { care settings, and (h) expand breastfeeding support }\end{array}$ \\
\hline $\begin{array}{l}\text { Increase } \\
\text { access }\end{array}$ & $\begin{array}{l}\text { (a) enroll more children in school meal programs, (b) maintain enrolling } \\
\text { additional } 4,500 \text { students per year to school meal programs, (c) allow more } \\
\text { universal meal access for students in high poverty communities, and (d) } \\
\text { provide meals for more vulnerable children in afterschool programs }\end{array}$ \\
\hline $\begin{array}{l}\text { Increase } \\
\text { program } \\
\text { monitoring }\end{array}$ & $\begin{array}{l}\text { (a) audit school districts every three years, (b) demand school districts to } \\
\text { make information more readily available to parents, (c) include provisions } \\
\text { to ensure the safety of school foods, and (d) provide training and technical } \\
\text { assistance for school food service providers }\end{array}$ \\
\hline
\end{tabular}

Coordinated School Health Program. The CDC (2011c) recommends the Coordinated School Health Program (CSHP) to improve students' health and learning in U.S. It is an organized set of programs, policies, and activities with eight components to promote students' health, achievement, and life success - health education, physical education, nutrition services, health services, counseling and social psychological services, healthy and safe school environment, family and community involvement, and health promotion for staff (CDC, 2011c). Table 2 describes the eight components of a CSHP. The goals of CSHP are to increase health knowledge, health attitudes, health skills, health behaviors, health outcomes, educational outcomes, and social outcomes for children (CDC, 2011c). 


\section{Table 2}

Eight components of a Coordinated School Health program

\begin{tabular}{|c|c|}
\hline Component & Description \\
\hline Health Education & $\begin{array}{l}\text { It includes a variety of health topics related to physical activity, } \\
\text { nutrition, alcohol tobacco or drug use, abuse, mental prevention, } \\
\text { sexual health, safety and injury prevention, and violence } \\
\text { prevention. It should address the National Health Education } \\
\text { Standards (CDC, 2011e). }\end{array}$ \\
\hline Physical Education & $\begin{array}{l}\text { It is a planned, sequential K-12 curriculum to improve students' } \\
\text { knowledge and skills for lifelong participation in physical } \\
\text { activity. }\end{array}$ \\
\hline Nutrition Services & $\begin{array}{l}\text { It requires school to provide meals meeting the U.S. Dietary } \\
\text { Guidelines for Americans. }\end{array}$ \\
\hline Health Services & $\begin{array}{l}\text { It ensures every child and family have the access to health care } \\
\text { services, emergency care for illness and injury, and educational } \\
\text { and counseling opportunities for maintaining and promoting } \\
\text { health. }\end{array}$ \\
\hline $\begin{array}{l}\text { Counseling \& Social } \\
\text { Psychological Services }\end{array}$ & $\begin{array}{l}\text { It ensures every student receive these services from school } \\
\text { counselors, psychologists and social workers, and aims to } \\
\text { improve students' mental, emotional and social health. }\end{array}$ \\
\hline $\begin{array}{l}\text { Healthy \& Safe School } \\
\text { Environment }\end{array}$ & $\begin{array}{l}\text { It is designed to obtain healthy physical and aesthetic } \\
\text { surroundings and psychosocial climate and culture of the } \\
\text { school. }\end{array}$ \\
\hline $\begin{array}{l}\text { Family \& Community } \\
\text { Involvement } \\
\text { Health Promotion for } \\
\text { Staff }\end{array}$ & $\begin{array}{l}\text { It requires the school to involve parents and engage community } \\
\text { resources and services to improve students' health. } \\
\text { It aims to provide health assessment, health education and } \\
\text { health-related fitness activities for school staff to pursue a } \\
\text { healthy lifestyle and improve their health status. }\end{array}$ \\
\hline
\end{tabular}

The CDC (2011c) has developed a coordinated model to implement a CSHP, consisting of (1) assessing school environment, (2) forming a school health/wellness council, (3) identifying a school health coordinator, (4) developing an action plan, (5) implementing the eight components, (6) focusing on students, (7) addressing priority health or risk behaviors, and (8) providing professional development for staff. To 
facilitate the implementation of this program, state education and health agencies should provide technical assistance, resource plan, political support, professional development, and evaluation system (CDC, 2011c). The Kentucky Department of Education (2012) calls upon all school districts to approve and adopt a CSHP to improve children's health and learning in school. To facilitate the adaptation and administration of CSHP, the Kentucky Department of Education (2012) proposed to: (1) provide leadership and support to develop a state-level infrastructure; (2) demonstrate an integrated, collaborative approach among educators, health service providers, and policy agencies; and (3) make sure every child has the access to health services and support. The Kentucky Department of Education has advocated this program to all the school districts, and provided resources and technical training to the schools.

\section{Statistical Methods Used in Repeated Measures Design}

\section{Multiple-Sample Repeated Measures ANOVA}

Multiple-sample repeated measures ANOVA, sometimes called "split-plots" ANOVA model, is the simplest and most commonly used, but most restrictive model used in longitudinal studies (Hedeker \& Gibbons, 2006). This method is used to examine the effects of two factors (one between-subject factor and one within-subject factor) on dependent variables. Suppose factor A is the between-subject factor with $s$ groups, and time is the within-subject factor with $n$ time points. For group $h$, there are $N_{h}$ subjects $\left(N=\sum_{h=1}^{S} N_{h}\right)$. There are four effects of interest - between-subject main effect (factor A effect or group effect), within-subject main effect (time effect or intervention effect), interaction effect between factor A and time, and random subject effects. The multiplesample repeated measures model can be written as: 


$$
y_{h i j}=\mu+\gamma_{h}+\tau_{j}+(\gamma \tau)_{h j}+\pi_{i(h)}+e_{h i j}
$$

Where:

$y_{h i j}$ is a $\left(s N_{s}\right) \times n$ response matrix, such as,

\begin{tabular}{cccccc}
\hline \multirow{2}{*}{ Group } & \multirow{2}{*}{ Subject } & \multicolumn{4}{c}{ Timepoints } \\
\cline { 3 - 6 } & & 1 & 2 & $\ldots$ & $n$ \\
\hline 1 & 1 & $y_{111}$ & $y_{112}$ & $\ldots$ & $y_{11 n}$ \\
1 & 2 & $y_{121}$ & $y_{122}$ & $\ldots$ & $y_{12 n}$ \\
1 & $\ldots$ & $\ldots$ & $\ldots$ & $\ldots$ & $\ldots$ \\
1 & $\ldots$ & $\ldots$ & $\ldots$ & $\ldots$ & $\ldots$ \\
1 & $N_{1}$ & $y_{1 N_{1} 1}$ & $y_{1 N_{1} 2}$ & $\ldots$ & $y_{1 N_{1} n}$ \\
$\ldots$ & $\ldots$ & $\ldots$ & $\ldots$ & $\ldots$ & $\ldots$ \\
$s$ & 1 & $y_{s 11}$ & $y_{s 12}$ & $\ldots$ & $y_{s 1 n}$ \\
$s$ & 2 & $y_{s 21}$ & $y_{s 22}$ & $\ldots$ & $y_{s 2 n}$ \\
$s$ & $\ldots$ & $\ldots$ & $\ldots$ & $\ldots$ & $\ldots$ \\
$s$ & $\ldots$ & $\ldots$ & $\ldots$ & $\ldots$ & $\ldots$ \\
$s$ & $N_{s}$ & $y_{s N_{s} 1}$ & $y_{s N_{S} 2}$ & $\ldots$ & $y_{s N_{S} n}$ \\
\hline
\end{tabular}

with $h=1, \ldots, s$ groups, $i=1, \ldots, N_{h}$ subjects in group $h\left(N=\sum_{h=1}^{S} N_{h}\right)$, and $j=1, \ldots, n$ time points.

$\mu$ is a constant, the grand mean.

$\gamma_{h}$ is the main effect of group $h\left(\sum_{h} \gamma_{h}=0\right)$.

$\tau_{j}$ is the main effect of time $j\left(\sum_{j} \tau_{j}=0\right)$.

$(\gamma \tau)_{h j}$ is the interaction effect between group $h$ and time $j\left(\sum_{h} \sum_{j}(\gamma \tau)_{h j}=0\right)$.

$\pi_{i(h)}$ is the individual difference component for subject $i$ nested in group $h$.

$e_{h i j}$ is the error for subject $i$ in group $h$ at time $j$.

The distributional assumptions for the above model are:

$$
\pi_{i(h)} \sim N\left(0, \sigma_{\pi}^{2}\right) \quad \text { and } \quad e_{h i j} \sim\left(0, \sigma_{e}^{2}\right)
$$

The variance-covariance structure follows compound symmetry: 


$$
\operatorname{Var}\left(y_{h i j}\right)=\left[\begin{array}{ccc}
\rho_{e}^{2}+\sigma_{\pi}^{2} & \cdots & \sigma_{\pi}^{2} \\
\cdots & \rho_{e}^{2}+\sigma_{\pi}^{2} & \cdots \\
\sigma_{\pi}^{2} & \cdots & \rho_{e}^{2}+\sigma_{\pi}^{2}
\end{array}\right]
$$

The sum of squares and expected mean squares for the repeated measures model are given in Table 3. To test the significance of random subject effects, the test statistics is $F_{S(A)}=M S_{S(A)} / M S_{R} \sim F_{N-S,(N-S)(n-1)}$. Compared to a univariate ANOVA, multiplesample repeated measures ANOVA uses a whole covariate matrix - variances and covariances as the error for the within-subject factor in the model. The variancecovariance structure used in the multiple-sample repeated measures ANOVA is compound symmetry, which assumes that all variances are the same with each other, and all the covariances are equal to one another over time (Kincaid \& COMSYS Information Technology Services, 2005). This assumption has little validity for longitudinal data, because typically, variances increase with time because some subjects respond and others do not, and covariances for proximal occasions are larger than covariances for distal occasions (Hedeker \& Gibbons, 2006). Moreover, this model can only allow each subject to have his/her own trend line in terms of intercept but not in slope. 


\section{Table 3}

Analysis of variance for two-factor experimental with repeated measures on time

\begin{tabular}{|c|c|c|c|c|}
\hline $\begin{array}{l}\text { Source of } \\
\text { Variation }\end{array}$ & $\begin{array}{c}\text { Sum of Squares } \\
(S S)\end{array}$ & $\begin{array}{c}\text { Degree of } \\
\text { Freedom }(d f)\end{array}$ & $\begin{array}{l}\text { Mean Squares } \\
\qquad(M S)\end{array}$ & $F$-ratio \\
\hline \multicolumn{5}{|c|}{ Between Subjects Effects } \\
\hline Factor A & $S S_{A}=n \sum_{h=1}^{s} N_{h}\left(\bar{y}_{h . .}-\bar{y}_{\ldots}\right)^{2}$ & $s-1$ & $M S_{A}=S S_{A} /(s-1)$ & $M S_{A} / M S_{S(A)}$ \\
\hline $\begin{array}{l}\text { Subjects } \\
\text { in Groups }\end{array}$ & $S S_{S(A)}=n \sum_{h=1}^{s} \sum_{i=1}^{N_{h}}\left(\bar{y}_{h i .}-\bar{y}_{h . .}\right)^{2}$ & $N-s$ & $M S_{S(A)}=S S_{S(A)} /(N-S)$ & \\
\hline \multicolumn{5}{|c|}{ Within Subjects Effects } \\
\hline Time $(\mathrm{T})$ & $S S_{T}=N \sum_{j=1}^{n}\left(\bar{y}_{. . j}-\bar{y}_{. . .}\right)^{2}$ & $n-1$ & $M S_{T}=S S_{T} /(n-1)$ & $M S_{T} / M S_{R}$ \\
\hline $\mathrm{T}^{*} \mathrm{~A}$ & $S S_{T A}=\sum_{h=1}^{s} \sum_{j=1}^{n} N_{h}\left(\bar{y}_{h . j}-\bar{y}_{h . .}-\bar{y}_{. . j}+\bar{y}_{. . .}\right)^{2}$ & $(s-1)(n-1)$ & $M S_{T A}=S S_{T A} /(s-1)(n-1)$ & $M S_{T A} / M S_{R}$ \\
\hline Residual & $S S_{R}=\sum_{h=1}^{S} \sum_{i=1}^{N_{h}} \sum_{j=1}^{n}\left(\bar{y}_{h i j}-\bar{y}_{h . j}-\bar{y}_{h i .}+\bar{y}_{h . .}\right)^{2}$ & $(N-s)(n-1)$ & $M S_{R}=S S_{R} /(N-s)(n-1)$ & \\
\hline Total & $S S y=\sum_{\mathrm{h}=1}^{\mathrm{s}} \sum_{\mathrm{i}=1}^{\mathrm{N}_{\mathrm{h}}} \sum_{\mathrm{j}=1}^{\mathrm{n}}\left(\overline{\mathrm{y}}_{\mathrm{hij}}-\overline{\mathrm{y}}_{. . .}\right)^{2}$ & $N n-1$ & & \\
\hline
\end{tabular}

Note. $\bar{y}_{\text {... }}=$ average across groups, time points, and subjects,

$\bar{y}_{h . .}=$ average for group $h$ across time points and subjects,

$\bar{y}_{. . j}=$ average for timepoint $j$ across groups and subjects,

$\bar{y}_{h i}=$ average for subject $i$ in group $h$ across time points,

$\bar{y}_{h . j}=$ average for group $h$ at time point $j$ across subjects. 


\section{Mixed-Effects Regression Models}

Mixed-effects regression models can be applied to both normally distributed continuous outcomes as well as categorical outcomes, and they are quite robust to missing data (Hedeker \& Gibbons, 2006). When analyzing repeated measures data, mixed-effects regression models can help to fit covariate pattern models with more appropriate fixed effects estimates. There is a large selection of variance-covariance structures used in mixed-effects regression models. Four forms of variance-covariance structures are popularly used in mixed-effects regression models: compound symmetry, unstructured, autoregressive and autoregressive heterogeneous variances (See Figure 1) (Kincaid \& COMSYS Information Technology Services, 2005). The unstructured form assumes that each variance and covariance is unique. The autoregressive structure has homogeneous variances, and correlations decline exponentially with distance, that is, two measurements that are right next to each other in time are more correlated than measurements that are more distant. The autoregressive heterogeneous variances structure has heterogeneous variances, and correlations decline exponentially with distance as the autoregressive structure (Kincaid \& COMSYS Information Technology Services, 2005).

$$
\begin{aligned}
& {\left[\begin{array}{ccc}
\sigma^{2}+\sigma_{1}^{2} & \sigma_{1}^{2} & \sigma_{1}^{2} \\
\sigma_{1}^{2} & \sigma^{2}+\sigma_{1}^{2} & \sigma_{1}^{2} \\
\sigma_{1}^{2} & \sigma_{1}^{2} & \sigma^{2}+\sigma_{1}^{2}
\end{array}\right] \quad\left[\begin{array}{ccc}
\sigma_{1}^{2} & \sigma_{12} & \sigma_{13} \\
\sigma_{12} & \sigma_{2}^{2} & \sigma_{23} \\
\sigma_{13} & \sigma_{23} & \sigma_{3}^{2}
\end{array}\right]} \\
& \text { Compound Symmetry } \\
& \text { Unstructured } \\
& {\left[\begin{array}{ccc}
\sigma^{2} & \rho \sigma^{2} & \rho^{2} \sigma^{2} \\
\rho \sigma^{2} & \sigma^{2} & \rho \sigma^{2} \\
\rho^{2} \sigma^{2} & \rho \sigma^{2} & \sigma^{2}
\end{array}\right] \quad\left[\begin{array}{ccc}
\sigma_{1}^{2} & \rho \sigma^{2} & \rho^{2} \sigma^{2} \\
\rho \sigma^{2} & \sigma_{2}^{2} & \rho \sigma^{2} \\
\rho^{2} \sigma^{2} & \rho \sigma^{2} & \sigma_{3}^{2}
\end{array}\right]}
\end{aligned}
$$

Autoregressive Autoregressive Heterogeneous Variances

Figure 1. Examples for variance-covariance structures 
Mixed-effects regression models can be written as:

$$
y_{i}=X_{i} \beta+Z_{i} v_{i}+\epsilon_{i}
$$

Where:

$y_{i}$ is a $n_{i} \times 1$ response vector for subject $i$, with $i=1 \ldots N$ subjects, and $n_{i}=$ number of repeated measurements for subject $i$.

$X_{i}$ is a $n_{i} \times p$ fixed design matrix, $p=$ number of fixed effects of interest (time effects, group effects, interaction effects).

$Z_{i}$ is a $n_{i} \times r$ random design matrix, $r=1$ or 2 number of random effects of interest (intercept and slope).

$\beta$ is a $p \times 1$ vector of fixed effects, the parameters of $\beta$ are the same for all subjects.

$v_{i}$ is a $r \times 1$ vector of random effects, the parameters of $v$ are allowed to vary among subjects.

$\epsilon_{i}$ is a $n_{i} \times 1$ residual vector.

Three assumptions are under this model: (1) residual is independent within subject, and follows normal distribution with mean 0 and variance $\sigma^{2},(2) \epsilon_{i}$ and $v_{i}$ are independent, and (3) $v_{i}$ follows normal distribution with mean 0 and variance $\sigma_{0}^{2}$ (random-intercepts model) and $\left(\begin{array}{cc}\sigma_{0}^{2} & \sigma_{01} \\ \sigma_{01} & \sigma_{1}^{2}\end{array}\right)$ (random intercepts and trend model) (Hedeker \& Gibbons, 2006).

\section{Summary}

Childhood obesity has become a national public health crisis in the U.S. Evidence supports that unhealthy behaviors - physical inactivity and unhealthy eating - are significantly correlated with the childhood obesity epidemic. Physical inactivity and 
unhealthy eating behaviors have broken the energy balance equation among children. In $2002,61.5 \%$ of children did not participate in any organized physical activity during nonschool hours and $22.6 \%$ of children did not engage in any free-time physical activity. In 2004, only $21 \%$ of children consumed the recommended five or more servings of fruits and vegetables a day, but half of the vegetable servings were fried potatoes. Therefore, programs focusing on healthy lifestyle play a promising role in preventing and controlling childhood obesity.

Both family-based and school-based healthy lifestyle programs have shown significant effects on reducing weight and sedentary activity, and increasing physical activity. School-based healthy lifestyle programs are cost-effective, and schools are considered as an ideal setting for healthy lifestyle promotion programs. Furthermore, rural residency has been deemed as a risk factor for children being overweight or obese, and participating in unhealthy behaviors. Therefore, comprehensive school-based programs have a promising role in promoting healthy lifestyle and preventing or controlling obesity among children, especially children in rural area. The purpose of this study was to assess the preliminary effects of a comprehensive school-based program on physical activity and healthy eating behavior among rural children from kindergarten to fifth grade in Kentucky using multiple-sample repeated measures ANOVA and mixedeffects regression models. 


\section{CHAPTER 3}

\section{METHODOLOGY}

\section{Research Design}

A Quasi-Experimental Design with repeated measures (intervention group only) was utilized to improve healthy behaviors - physical activity and eating behavior among rural children. All children from kindergarten to fifth grade in four rural elementary schools in Kentucky were recruited to participate in the study. University Institutional Review Board (IRB) reviewed and approved the protocol. All participants were assessed at baseline (January 2010) and started the program immediately. Follow-up assessments were conducted to assess children's physical activity level and eating behavior in February (time 1, t1), March (t2), April (t3), and May (t4) of the first year of the program in 2010.

\section{Measurements}

\section{Physical Activity}

The number of steps recorded by pedometer was used to assess physical activity level, with more step counts indicating a higher level of physical activity. All children were asked to wear a pedometer for consecutive four days each time (baseline and four follow-up tests), and the average steps of the four days were used to describe the levels of physical activity among children. A pedometer log (See Appendix A) was created for children to record their steps each day. In the pedometer log, children were asked to 
write down their number of steps and the time and date the number was recorded.

Moreover, the pedometer log included detailed instructions for the parents/guardians to supervise or help their children wear the pedometer, record the steps, and reset to zero. Each time on Wednesday morning, classroom teachers handed the pedometers out to children. Children were asked to attach the pedometer to the waistband of his/her clothing in the morning from Wednesday to Saturday, and each night, the pedometer was to be removed before bedtime. At bedtime, children recorded the step counts on the pedometer logs. Once that day's steps had been recorded, children were asked to reset the pedometer to zero. After Day 4 (Saturday), children were asked to return the pedometers and pedometer $\log$ s to their classroom teacher on the following Monday.

The CDC (2011d) and U.S. Department of Health and Human Services (2012) recommend that children should participate in 60 minutes or more of moderate- or vigorous-intensity physical activity every day. With the technological advancement of objective measurement of physical activity level, such as pedometers, a new recommendation was informed to obtain the public health guidelines for children in terms of steps/day (Tudor-Locke et al., 2011). In 2008, a sex-specific graduated step index was introduced for children aged 6 to 12 years old. Values for boys were: < 10,000 steps/per day (sedentary); 10,000-12,499 steps/per day (low active); 12,500-14,999 (somewhat active); 15,000-17,499 (active); $\geq 17,500$ (highly active). The corresponding values for girls were: $<7,000 ; 7,000-9,499 ; 9,500-11,999 ; 12,000-14,499 ; \geq 14,500$ (Tudor-Locke, Hatano, Pangrazi, \& Kang, 2008). In addition, evidence suggests that 13,000 steps/per day for boys and 11,000 steps/per day for girls provided reasonable estimation of 
attainment of 60 minutes of moderate- or vigorous-intensity physical activity (TudorLocke et al., 2011).

\section{Eating Behavior}

Five items (See Appendix B) selected from the School Physical Activity and Nutrition (SPAN) questionnaire were used to assess children's eating behavior (Penkilo, George, \& Hoelscher, 2008; Thiagarajah et al., 2008). The eating behavior was described by the number of times consuming fruits and vegetables on the previous day. Evidence has supported that the SPAN questionnaire has relatively good test-retest reliability with Spearman rank order correlations (test-retest correlations) of 0.79 and 0.78 , Kappa values (inter-rater agreement) of 0.65 and 0.60 , and percentage agreement of $74.3 \%$ and $70.3 \%$ for vegetable and fruit items respectively among children (Penkilo et al., 2008). In addition, it has acceptable validity with Spearman rank order correlations of 0.34 and 0.40 , Kappa values of 0.17 and 0.27 , and percentage of agreement of $27 \%$ and $51 \%$ between the SPAN questionnaire and a 24-recall scale for vegetable and fruit items (Thiagarajah et al., 2008). In this study, the Cronbach's alpha coefficient was 0.73 , and the item-item correlation coefficients ranged from 0.30 to 0.41 , indicating that the fiveitem nutrition scale had acceptable reliability.

\section{Setting}

Subjects in this study were recruited from four rural elementary schools in Kentucky. In School 1, there were total 370 students (184 boys and 179 girls) in grades PK-5, 19 classroom teachers with student/teacher ratio of 19.5 , and 250 students were eligible for free lunch, and 41 student were eligible for reduced-price lunch. In School 2, total students number was 277 (137 boys and 139 girls), classroom teachers 14.3, with 
student/teacher ratio of 19.4, and 157 students were eligible for free lunch, and 26 students were eligible for reduced-price lunch. In School 3, there were total 309 students (139 boys and 139 girls) and 16 classroom teachers with student/teacher ratio of 19.3 , and 198 students are eligible for free lunch, and 14 students were eligible for reduced-price lunch. While in School 4, there were total 459 students (247 boys and 200 girls) and 24.7 classroom teachers with student/teacher ratio of 18.6, and 231 students were eligible for free lunch, and 53 students were eligible for reduced-price lunch (National Center for Educational Statistics, 2012).

\section{Intervention}

The intervention is an integrated, multicomponent healthy lifestyle program based on the principles of the Coordinated School Health Program recommended by CDC (2011c). The intervention included four goals: (1) improving physical activity level, (2) improving health and nutrition education (U.S. Department of Health and Human Services, 2012), (3) promoting family/community involvement, and (4) realigning school's wellness policy with HealthierUS School Challenge (U.S. Department of Agriculture, 2011b). Interventions for all four goals (See Table 4) were conducted in the four schools, except Family Fitness Fun Night was cancelled in School 4 due to time constraints in the school year.

After receiving the funding, a project director, a nutrition consultant, a professional development consultant, a physical education consultant and three Healthy Lifestyle Coaches (HLCs) were hired to implement all activities. The three HLCs worked daily in the 4 schools (one HLC shared 2 schools) implementing the program and collecting data. Activities during the Family Fitness Fun Night included fruits and 
Table 4

Elementary school-based intervention goals, descriptions, and key personnel

\begin{tabular}{|c|c|c|}
\hline Goals & Description & Key Personnel \\
\hline $\begin{array}{l}\text { Improve Physical } \\
\text { Activity Level }\end{array}$ & $\begin{array}{l}\text { 1. Developed improved pedagogy strategies } \\
\text { 2. Implemented SPARK (Sports, Play, and Active } \\
\text { Recreation for Kids) physical education curriculum } \\
\text { (SPARK, 2012) } \\
\text { 3. Incorporated physical activity breaks into school }\end{array}$ & $\begin{array}{l}\text { Physical education consultant from local university } \\
\text { Each school's physical education teacher }\end{array}$ \\
\hline $\begin{array}{l}\text { Improve Health and } \\
\text { Nutrition Education }\end{array}$ & $\begin{array}{l}\text { 1. Participated in six HealthierUS School Challenge } \\
\text { nutrition curriculum workshops } \\
\text { 2. Attended one national school nutrition conference } \\
\text { 3. Provided one-day intensive classroom nutrition } \\
\text { education session } \\
\text { 4. Incorporated nutrition education into the curriculum } \\
\text { 5. Aligned lunch menus with the U.S. Department of } \\
\text { Agriculture's Nutrition Guidelines (2012) }\end{array}$ & $\begin{array}{l}\text { Each school's nutrition personnel (cafeteria } \\
\text { managers, cooks, and servers) } \\
\text { Each school's nutrition personnel } \\
\text { Local nutritional non-profit organization } \\
\text { Classroom teachers } \\
\text { Healthy Lifestyle Coaches Nutrition director }\end{array}$ \\
\hline $\begin{array}{l}\text { Promote } \\
\text { Family/Community } \\
\text { Involvement }\end{array}$ & $\begin{array}{l}\text { 1. Hosted Family Fitness Fun nights } \\
\text { 2. Strengthened family and community partnerships }\end{array}$ & $\begin{array}{l}\text { Healthy Lifestyle Coaches } \\
\text { County health departments, local hospitals, } \\
\text { universities, and other community health-related } \\
\text { groups }\end{array}$ \\
\hline $\begin{array}{l}\text { Realign School's } \\
\text { Wellness Policy } \\
\text { With HealthierUS } \\
\text { School Challenge }\end{array}$ & $\begin{array}{l}\text { 1. Developed and/or revised school wellness policy } \\
\text { 2. Aligned school wellness policy with national and state } \\
\text { physical activity and nutrition standards, and } \\
\text { Coordinated School Health models' framework (CDC, } \\
\text { 2011c) }\end{array}$ & $\begin{array}{l}\text { Healthy Lifestyle Coaches } \\
\text { Each school's site-based decision making council }\end{array}$ \\
\hline
\end{tabular}


vegetables taste-testing, physical activity obstacle courses, health and fitness booths and educational literature.

\section{Procedure}

Before the baseline data collection, the study protocol was submitted to the University of Louisville IRB for review. Since the lifestyle promotion programs would be adopted and implemented as part of the normal school day practices, the University IRB marked this study as "exempt". Then a letter was sent home to parents indicating that their children's school had been selected to participate in the program, and a variety of healthy interventions were to occur throughout the next 3 years. Children's participation in the data collection was voluntary. For children whose parents contacted the principal and asked for their child to be excluded from this study, their data were not collected. Approximately 10 children's parents requested for their children not to participate in the data collection.

Children in the study were asked to wear the pedometer each day and complete their pedometer logs each night with the help of their parents. At the end of each data collection window, the HLCs collected the pedometer logs and pedometers from each child during class, and asked the children to finish the nutrition questionnaire at the same time.

\section{Data Analysis}

Data was compiled and analyzed using SAS 9.3 for Windows (SAS Institute Inc, Cary, NC). Means $(M)$ and standard deviations $(S D)$ were applied to describe numerical variables, while frequencies and percentages were used to describe categorical variables. Multiple-sample repeated measures ANOVA was applied to assess the main effects of 
school, age, sex, and grade through tests on the mean squared errors between subjects, and the intervention effects and interaction effects through tests on the mean squared errors within subjects. Independent t-test was utilized to test sex differences on physical activity level, and fruits and vegetables consumption, while one-way ANOVA was applied to test the school and grade differences on physical activity level, and fruits and vegetables consumption over time. Cochran-Mantel-Haenszel Statistics was used when the dependent variables were percentage. Simple linear regression was used to explore the influence of age on physical activity level and eating behavior. Mixed-effects regression models were applied to assess the change trends of physical activity level and eating behavior over time and to explore the fitted model for physical activity and eating behavior. Akaike's Information Criterion (AIC) (smaller is better) was used to select the best approximating model.

\section{Sample}

There were 1,508 children, 814 boys and 679 girls (15 children did not indicate sex $)$, participating in this study with an average age of 8.32 years old $(S D=1.88)$. Table 5 displays the demographics distribution of the subjects in this study. The results of ANOVA indicated that there were significant differences among schools in children's age $(F=82.39, p<0.001)$. Specifically, children from School 4 were older on average than children from School 1, 2 and 3, and children from School 1 were older than children from School 2 and 3. Thus, for inferential analysis among these four schools, age was controlled. 


\section{Table 5}

Demographic information of subjects

\begin{tabular}{lccccc}
\hline Variables & Overall & School 1 & School 2 & School 3 & School 4 \\
\hline Total & 1508 & $492(32.6 \%)$ & $242(16.1 \%)$ & $323(21.4 \%)$ & $451(29.9 \%)$ \\
Grades & & & & & \\
Grade K & $236(15.6 \%)$ & $81(16.5 \%)$ & $35(14.5 \%)$ & $51(15.8 \%)$ & $69(15.3 \%)$ \\
Grade 1 & $232(15.4 \%)$ & $71(14.4 \%$ & $36(14.9 \%)$ & $52(16.1 \%)$ & $73(16.2 \%)$ \\
Grade 2 & $263(17.4 \%)$ & $91(18.5 \%)$ & $42(17.4 \%)$ & $53(16.4 \%)$ & $77(17.1 \%)$ \\
Grade 3 & $265(17.6 \%)$ & $72(14.6 \%)$ & $46(19.0 \%)$ & $73(22.6 \%)$ & $74(16.4 \%)$ \\
Grade 4 & $265(17.6 \%)$ & $98(19.9 \%)$ & $36(14.9 \%)$ & $40(12.4 \%)$ & $91(20.2 \%)$ \\
Grade 5 & $247(16.4 \%)$ & $79(16.1 \%)$ & $47(19.4 \%)$ & $54(16.7 \%)$ & $67(14.9 \%)$ \\
Sex & & & & & \\
Boys & $814(54.5 \%)$ & $263(53.5 \%)$ & $140(58.1 \%)$ & $165(51.7 \%)$ & $246(55.8 \%)$ \\
Girls & $679(45.5 \%)$ & $229(46.5 \%)$ & $101(41.9 \%)$ & $154(48.3 \%)$ & $195(44.2 \%)$ \\
Age & $8.3 \pm 1.9$ & $8.3 \pm 1.8$ & $7.6 \pm 1.7$ & $7.5 \pm 1.7$ & $9.3 \pm 1.6$ \\
& $(5-13)$ & $(5-12)$ & $(5-10)$ & $(5-10)$ & $(6-13)$ \\
\hline
\end{tabular}




\section{CHAPTER 4}

\section{RESULTS}

\section{Physical Activity}

\section{Physical Activity Recommendation}

At baseline, $11(1.6 \%)$ girls and $9(1.1 \%)$ boys participated in at least 60 minutes moderate- or vigorous-intensity physical activity per day, that is, 13,000 steps/per day for boys and 11,000 steps/per day for girls. At t1, t2, t3 and $\mathrm{t} 4$, the number of girls meeting physical activity recommendation was $13(1.9 \%), 33(4.9 \%), 31(4.6 \%)$, and $46(6.9 \%)$ respectively, while the number of boys was 30 (3.7\%), 27 (3.3\%), 37 (4.5\%), and 33 $(4.1 \%)$ respectively.

The results of Cochran-Mantel-Haenszel statistics showed that the intervention had significant effects on the percentage of children meeting physical activity recommendation $(p<0.001)$. At $t 1$, the percentage of girls meeting physical activity recommendation was lower than the percentage of boys meeting physical activity recommendation $(p=0.04)$, while at $t 4$, the percentage of girls meeting physical activity recommendation was higher than the percentage of boys meeting physical activity recommendation $(p=0.02)$. Specifically, from baseline to $t 2, \mathrm{t} 3$ and $\mathrm{t} 4$, the percentage of girls meeting physical activity recommendation increased significantly $(p<0.01)$; and from baseline to $\mathrm{t} 1, \mathrm{t} 2, \mathrm{t} 3$ and $\mathrm{t} 4$, the percentage of boys meeting physical activity recommendation increased significantly $(p<0.01)$. Similarly, from $t 1$ to 2 , the 
percentage of girls meeting physical activity recommendation increased significantly $(p=$ 0.003).

\section{Multiple-sample Repeated Measures ANOVA}

The between subject tests of repeated measures ANOVA indicated that there were significant school effects $(p<0.001)$ and age effects $(p<0.001)$ on the physical activity level assessed by pedometer. The results of ANOVA indicated that the effects of intervention on physical activity level were significantly different among the four schools from baseline to 4 . The results of Tukey's HSD indicated that at baseline, children in School 3 participated in the lowest level of physical activity while children in School 1 had the highest level of physical activity (3437.21 vs. 5481.95, $p<0.001)$. At t1, children in School 2 had the lowest level of physical activity while children in School 1 engaged in the highest level of physical activity (4550.88 vs. 5740.94, $p<0.001$ ). At $\mathrm{t} 2$, children in School 2 had the lowest level of physical activity while children in School 1 had the highest level of physical activity (5015.82 vs. 6699.22, $p<0.001)$. At $\mathrm{t} 3$, children in School 4 participated in the lowest level of physical activity (School 4 did not have the Family Fitness Fun Night) while children in School 3 participated in the highest level of physical activity $(5966.35$ vs. $7788.82, p<0.001)$. At t4, children in School 4 had the lowest level of physical activity while children in School 3 had the highest level of physical activity $(6606.99$ vs. $7982.75, p<0.001)$.

The results of simple linear regression indicated that from baseline to $t 4$, children's physical activity level increased as children grew (physical activity = $399.4+243.1 \times$ age +2936.0$)$. The within subject test indicated that there were significant time effects $(p<0.001)$, interaction effects between time and school $(p<$ 
$0.001)$, and interaction effects between time and age $(p=0.031)$ on physical activity

level. In other words, time or intervention had significant effects on physical activity, and the effects of intervention depended on which school were the children in and the age of the children.

There was significant sex effects $(p<0.001)$, time effects $(p<0.001)$, but no significant interaction effects between time and sex $(p=0.328)$ on physical activity level. Specifically, at $\mathrm{t} 1, \mathrm{t} 2$, and $\mathrm{t} 3$, boys participated in significantly higher level of physical activity than girls. The effects of intervention on physical activity did not depend on sex. There was significant grade effects $(p<0.001)$, time effects $(p<0.001)$, and interaction effects between time and grade $(p<0.001)$ on the physical activity level recorded by pedometer. In other words, the effects of intervention depended on which grade were the children in.

\section{Mixed-Effects Regression Models}

Figure 2 demonstrates that there was an increasing linear trend of physical activity level over time among all schools, and there were unequal linear regressions of physical activity on time for the four schools $(p<0.001)$. Physical activity level increased dramatically among children in School 3, while increased slower among children in School 4. Figure 3 shows that there was an increasing linear trend of physical activity over time according to sex $(p<0.001)$. Figure 4 reveals that physical activity level increased linearly over time among children from different grades $(p<0.001)$, and physical activity level increased more slowly from baseline to t4 among children from kindergarten than students from other grades. The best approximating model for physical activity with AIC of $138.74 \times 10^{3}$ was shown in Table 6 . The results of physical activity 
model indicated that the average step counts at baseline were 4809.26. The conditional on average step counts (when controlling for other factors) increased by 273.8 per month, and increased by 288.39 with one grade level increasing. For each individual, the baseline physical activity level was different.

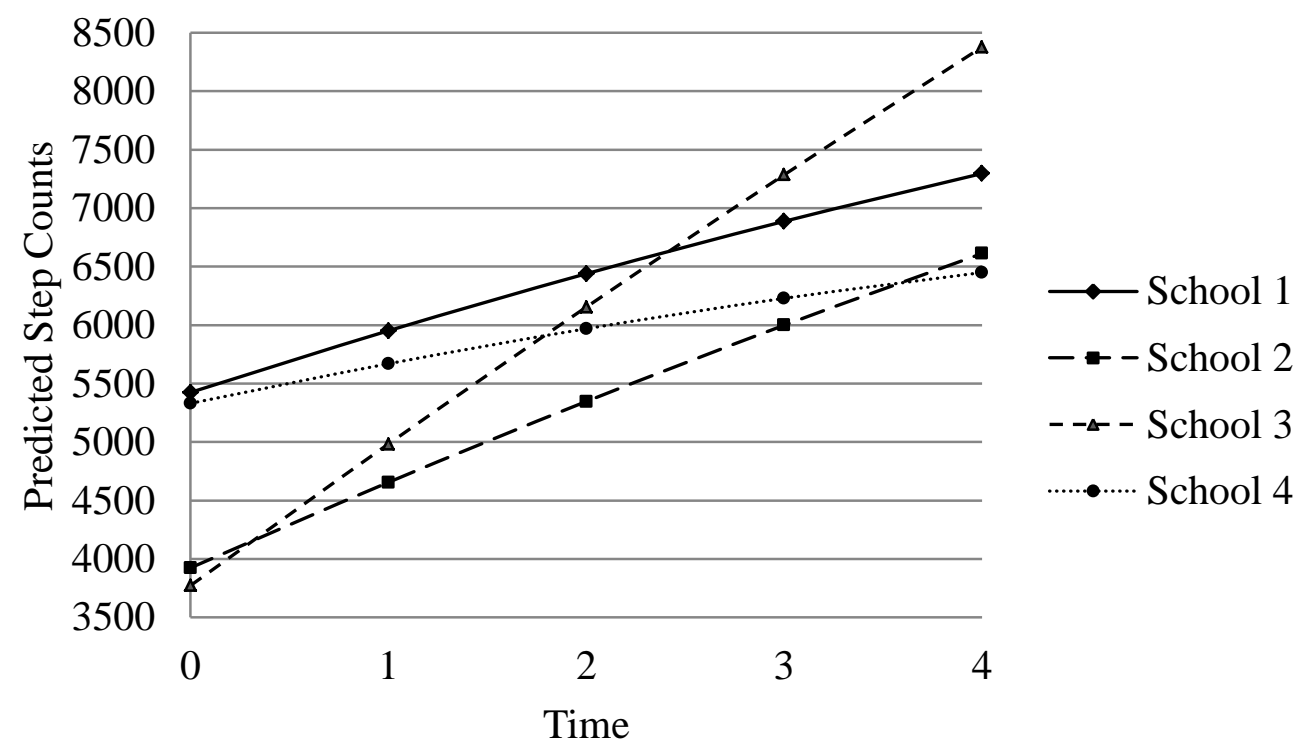

Figure 2. School-wised trend of children's physical activity level over time

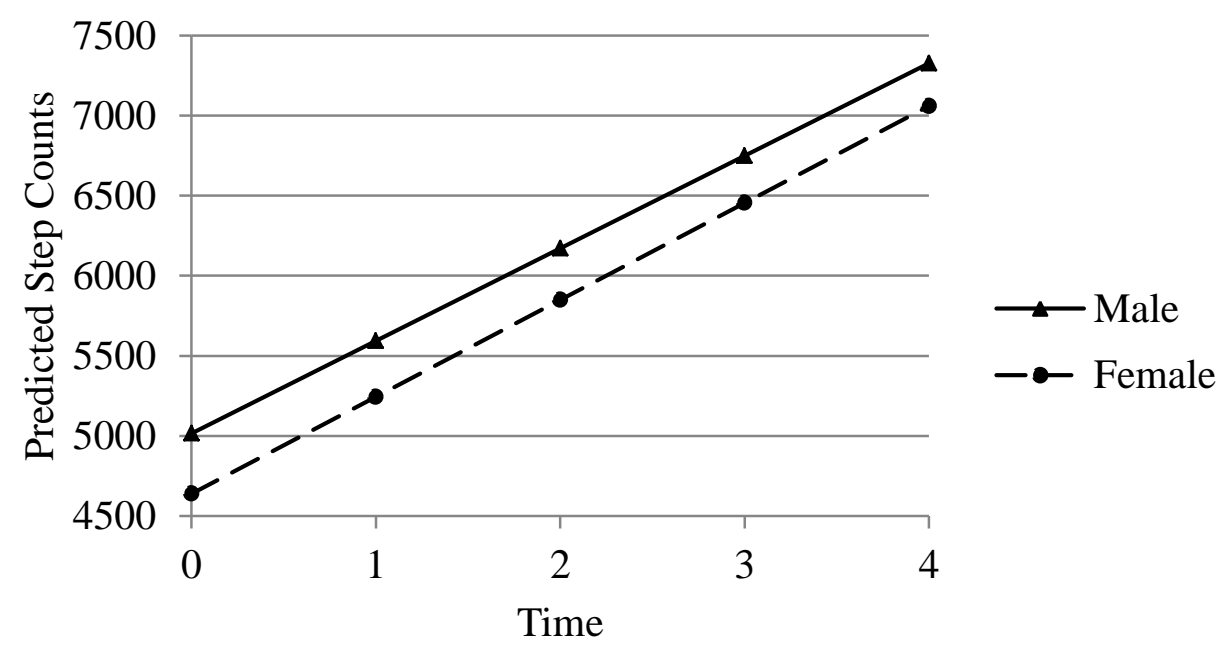

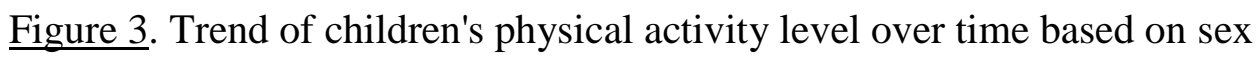




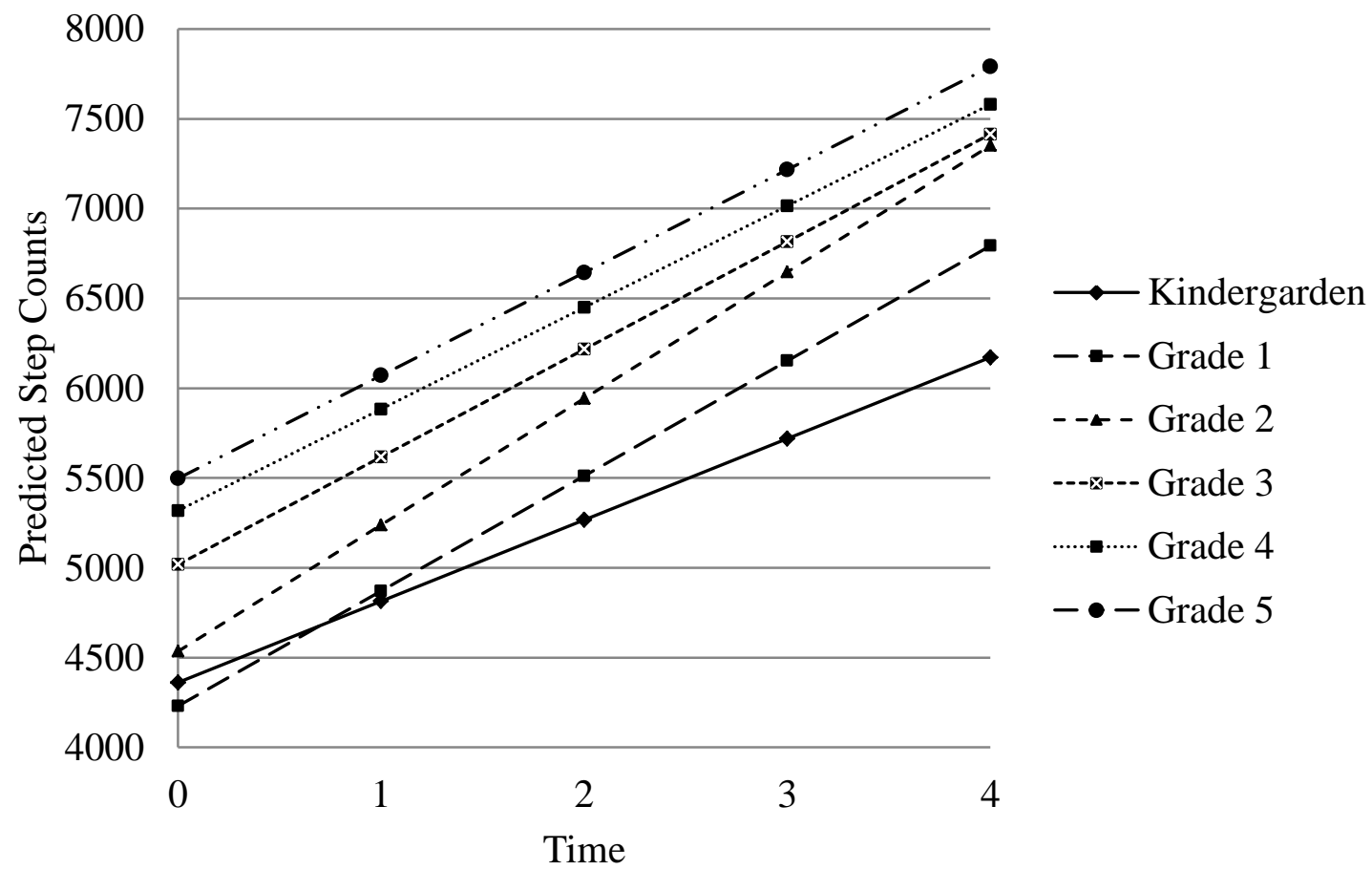

Figure 4. Trend of children's physical activity level over time based on grade level

\section{Eating Behavior}

\section{Nutrition Recommendation}

At baseline, 206 (14.8\%) children met the recommendation of eating three or more servings of vegetables and two or more servings of fruits per day. At $\mathrm{t} 1, \mathrm{t} 2, \mathrm{t} 3$ and t4, the number of children meeting the nutrition recommendation was 209 (15.3\%), 384 (27.8\%), 410 (30.2\%), and 347 (25.9\%) respectively. The results of Cochran-Mantel-

Haenszel statistics showed that the intervention had significant effects on the percentage of children meeting nutrition recommendation $(p<0.001)$. Specifically, from baseline to $\mathrm{t} 2, \mathrm{t} 3$, and $\mathrm{t} 4$, the percentage of children meeting nutrition recommendation increased significantly $(p<0.001)$. Similarly, from t1 to 2 , the percentage of children meeting nutrition recommendation increased significantly $(p<0.001)$, but from $\mathrm{t} 3$ to $t 4$, the 
percentage of children meeting nutrition recommendation decreased significantly $(p=$ $0.012)$.

\section{Multiple-sample Repeated Measures ANOVA}

There were significant school effects $(p<0.001)$ but no significant age effects $(p$ $=0.584)$ on the previous day fruits and vegetables consumption. From baseline to t 4 , children in School 1 consumed more fruits and vegetables than children from other schools. The results of simple linear regression indicated that at baseline, the previous day fruits and vegetables consumption significantly increased with age $(\hat{\beta}=0.075, p=$ 0.004). The within subject test indicated that there were significant intervention effects ( $p$ $<0.001)$, interaction effects between time and school $(p<0.001)$, and interaction effects between time and age $(p=0.011)$ on the previous day fruits and vegetables consumption. In other words, the effects of intervention on previous day fruits and vegetables consumption depended on which school were the children in and the age of the children.

There was significant sex effects $(p=0.006)$, time effects $(p<0.001)$, but no significant interaction effects between time and $\operatorname{sex}(p=0.245)$ on the previous day fruits and vegetables consumption. Specifically, at $\mathrm{t} 2, \mathrm{t} 3$, and $\mathrm{t} 4$, girls consumed more fruits and vegetables than boys. The effects of intervention on fruits and vegetables consumption did not depend on sex. The between subject tests indicated that there was no significant grade effects $(p=0.786)$ on the previous day fruits and vegetables consumption. The within subject test showed that there were significant time effects $(p<$ $0.001)$, and interaction effects between time and grade $(p<0.001)$ on the previous day fruits and vegetables consumption. In other words, the effects of intervention depended on which grade were the children in. The results of ANOVA indicated that at $\mathrm{t} 1$, children 
in Grade 4 consumed more fruits and vegetables than children in Grade 3 (4.21 vs. 3.91, $p=0.040)$.

\section{Mixed-Effects Regression Models}

Figure 5 displays that there was an increasing quadratic trend of previous day fruits and vegetables consumption over time among the four schools, and there were unequal quadratic regression of eating behavior on time for the four schools $(p<0.05)$. From baseline to 2 , the previous day fruits and vegetables consumption increased dramatically, while from $\mathrm{t} 2$ to $\mathrm{t} 4$, the consumption increased slowly or kept the same among children. The previous day fruits and vegetables consumption increased slower among children in School 4. Figure 6 demonstrates that there was an increasing quadratic trend of the previous day fruits and vegetables consumption over time among all children, and consumption increased faster among girls compared to boys $(p=0.01)$. Figure 7 reveals that there was an increasing quadratic trend of previous day fruits and vegetables consumption over time among children from different grades. From baseline to t3, the previous day fruits and vegetables consumption increased stably, while from t 3 to $t 4$, the consumption increased slowly or did not increase among all grades children. The best approximately model for eating behavior with AIC of $40.89 \times 10^{3}$ was shown in Table

6. The eating behavior model indicated that the average fruits and vegetables consumption at baseline was 2.88 . On average, the previous day fruits and vegetables consumption increased by 1.03 fruit or vegetable per month when controlling for other factors. For each individual, the baseline fruits and vegetables consumption was different, and also the increasing trend was different over time. 


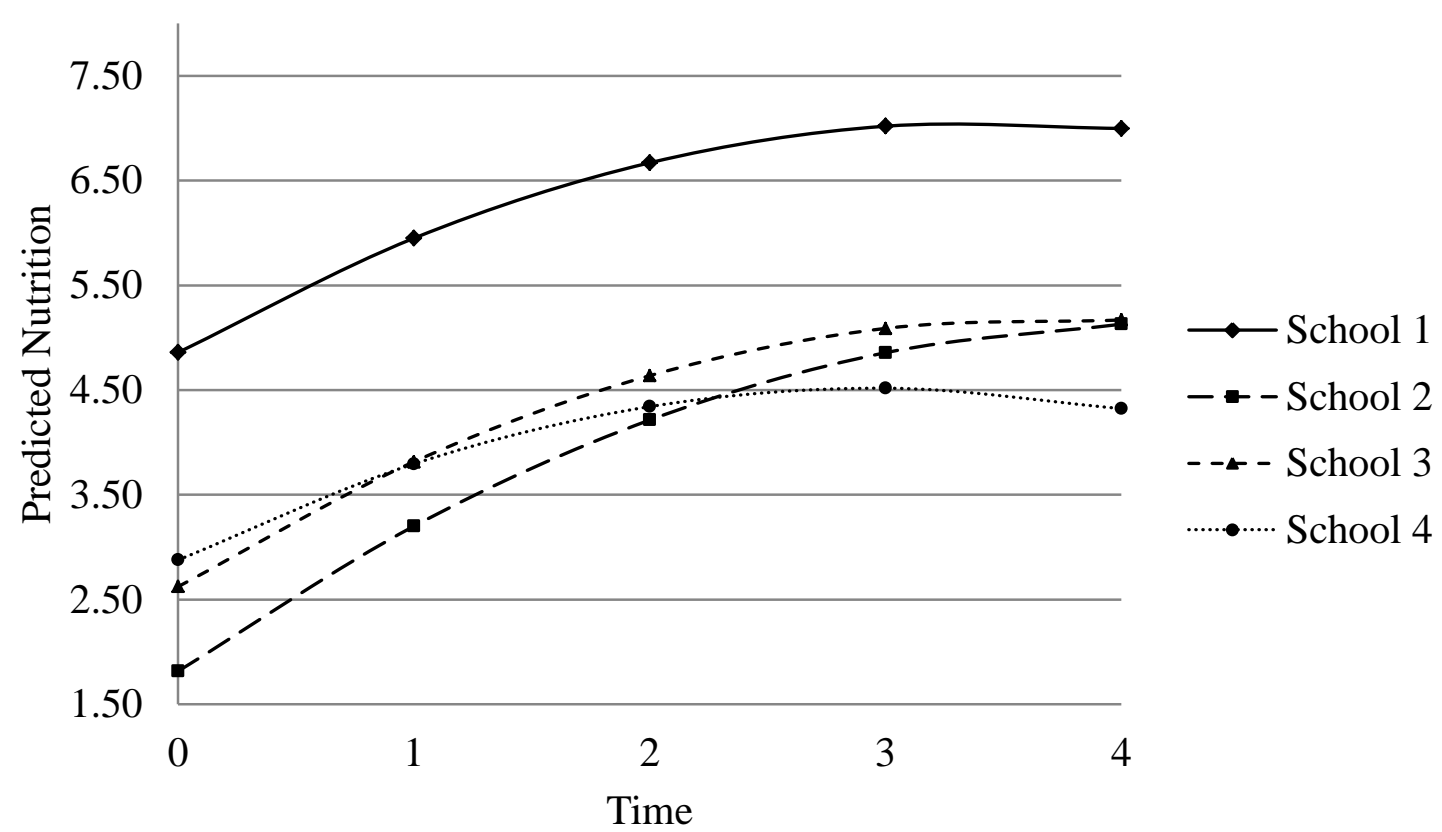

Figure 5. School-wised trend of children's eating behavior over time

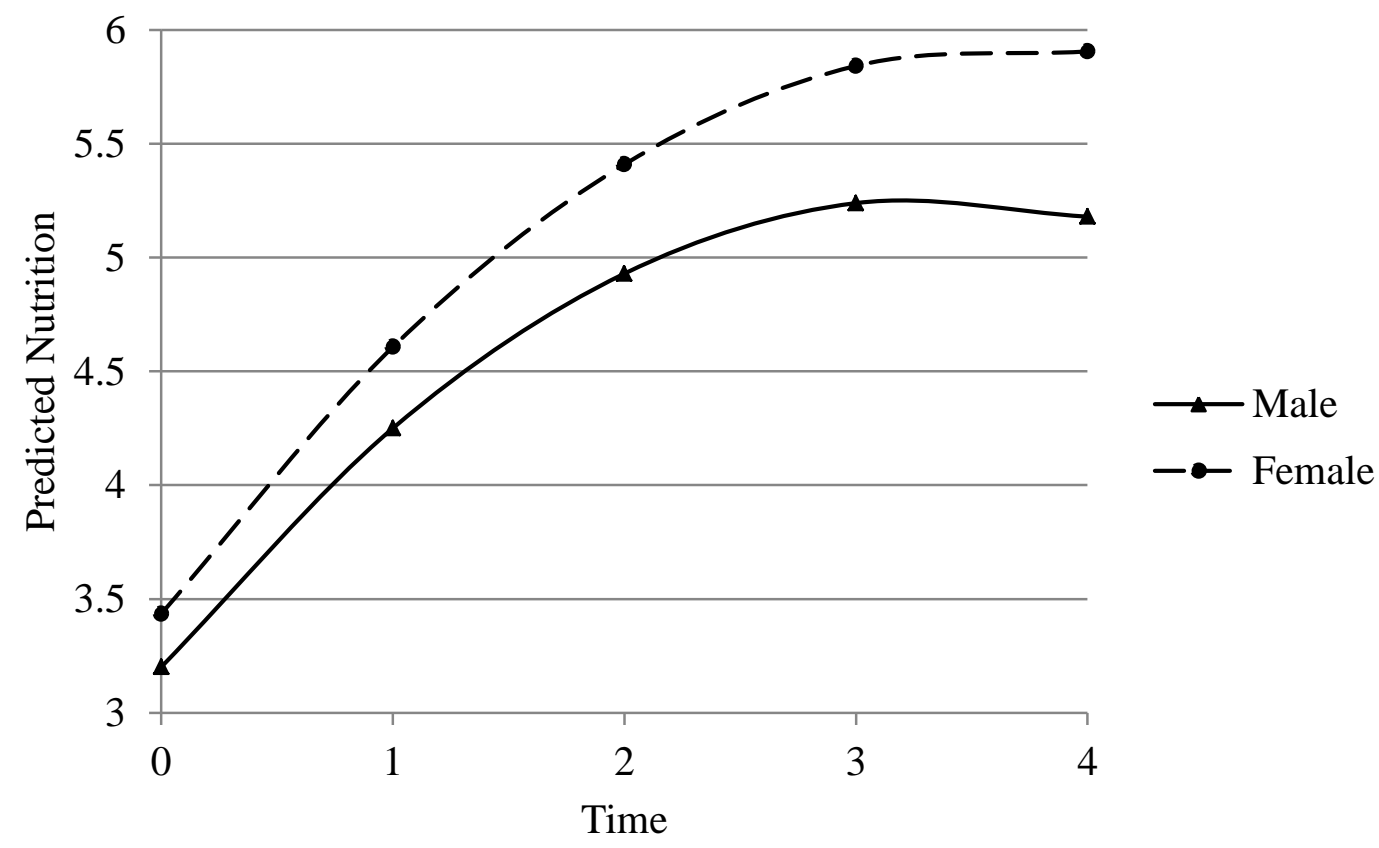

Figure 6. Trend of children's eating behavior over time based on sex 


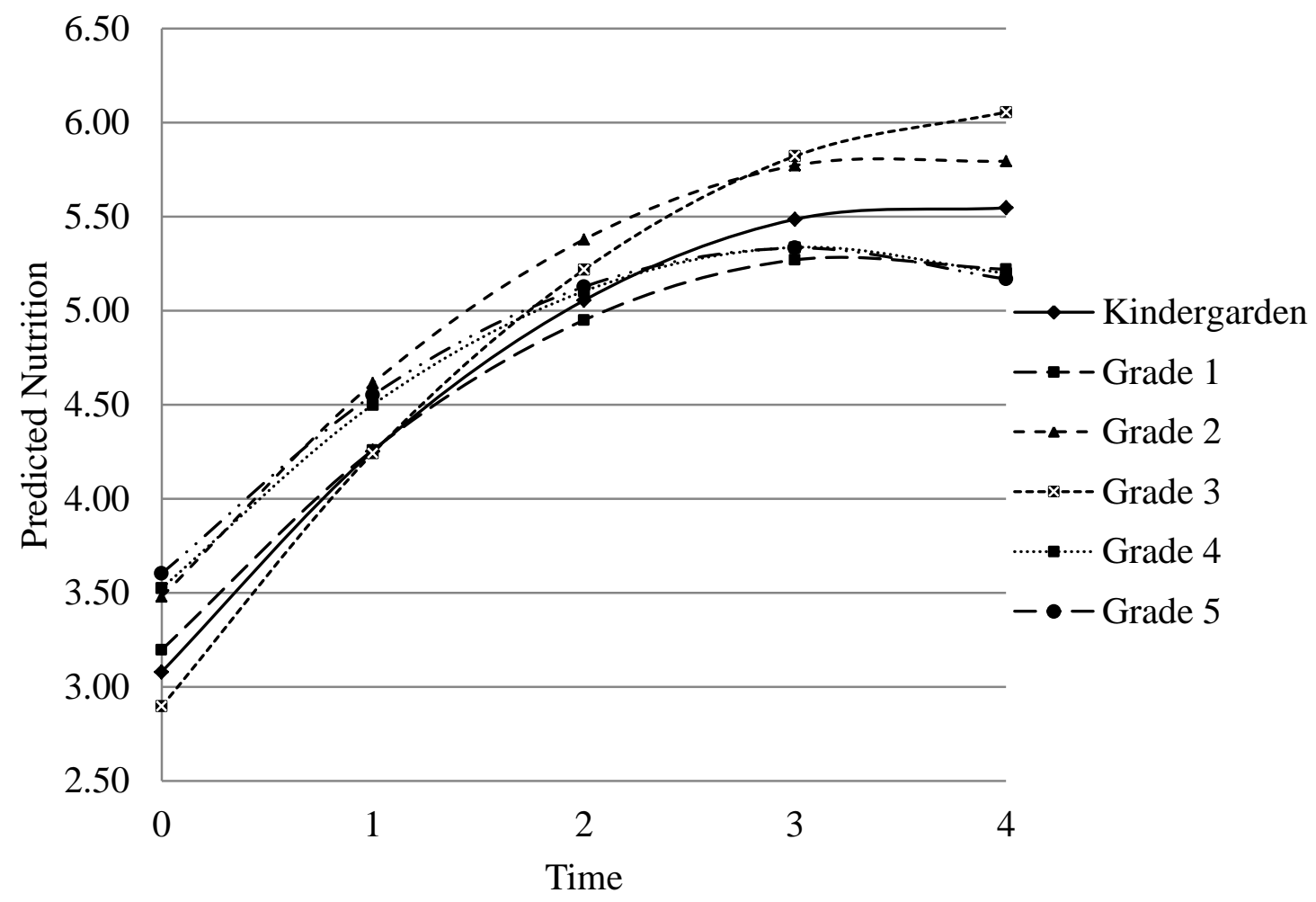

Figure 7. Trend of children's eating behavior over time based on grade level 


\section{Table 6}

$\underline{\text { Physical activity and eating behavior change over time }}$

\begin{tabular}{|c|c|c|c|c|}
\hline \multirow[t]{2}{*}{ Effect } & \multicolumn{2}{|c|}{ Physical Activity Model } & \multicolumn{2}{|c|}{ Eating Behavior Model } \\
\hline & Coefficient $(S E)$ & $p$-value & Coefficient $(S E)$ & $p$-value \\
\hline \multicolumn{5}{|l|}{ Fixed effects } \\
\hline Intercept & $4809.3(132.6)$ & $<0.001$ & $2.9(0.2)$ & $<0.001$ \\
\hline Time & $273.8(36.5)$ & $<0.001$ & $1.0(0.1)$ & $<0.001$ \\
\hline Time*Time & & & $-0.2(0.02)$ & $<0.001$ \\
\hline Sex (female) & $-373.6(87.6)$ & $<0.001$ & 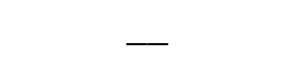 & - \\
\hline Grade & $288.4(26.0)$ & $<0.001$ & & \\
\hline School 1 & $92.3(149.4)$ & 0.54 & $2.0(0.2)$ & $<0.001$ \\
\hline School 2 & $-1457.6(182.5)$ & $<0.001$ & $-1.1(0.3)$ & $<0.001$ \\
\hline School 3 & $-1535.5(167.5)$ & $<0.001$ & $-0.3(0.2)$ & 0.27 \\
\hline Time*School 1 & $194.1(50.2)$ & $<0.001$ & $0.2(0.1)$ & 0.03 \\
\hline Time*School 2 & $398.6(61.4)$ & $<0.001$ & $0.5(0.1)$ & $<0.001$ \\
\hline Time *School3 & $882.2(56.3)$ & $<0.001$ & $0.3(0.1)$ & $<0.01$ \\
\hline \multirow[t]{2}{*}{ Time*Sex (female) } & - & - & $0.2(0.1)$ & 0.01 \\
\hline & \multicolumn{2}{|c|}{ Variance Estimate } & \multicolumn{2}{|c|}{ Variance Estimate } \\
\hline \multicolumn{5}{|l|}{ Random effects } \\
\hline Intercept & \multicolumn{2}{|c|}{$167 \times 10^{4}$} & \multicolumn{2}{|l|}{5.1} \\
\hline Time & $=$ & & \multicolumn{2}{|l|}{0.7} \\
\hline Residual & \multicolumn{2}{|c|}{5867055} & \multicolumn{2}{|l|}{9.2} \\
\hline
\end{tabular}

Note. $S E=$ standard error

\section{Fruits Consumption}

There were significant school effects $(p<0.001)$ and age effects $(p=0.047)$ on the previous day fruits consumption. The results of linear regression indicated that the previous day fruits consumption increased with age at baseline $(\hat{\beta}=0.064, p=$ $0.014)$ and $\mathrm{t} 1(\hat{\beta}=0.062, p=0.017)$. From baseline to $t 4$, the effects of intervention on previous day fruits consumption were significantly different among the four schools. Children in School 1 consumed more fruits over time than children in other schools. The within subject test indicated that there were significant intervention effects $(p=0.002)$, and interaction effects between time and school $(p<0.001)$, but no significant interaction 
effects between time and age $(p=0.322)$ on the previous day fruits consumption. In other words, the effects of intervention depended on which school were the children in instead of age.

The between subject tests revealed that there was significant sex effects $(p=$ 0.012) on the previous day fruits consumption. The within subject test indicated that there were significant time effects $(p<0.001)$, but no significant interaction effects between time and sex $(p=0.855)$ on the previous day fruits consumption. Specifically, at $\mathrm{t} 3$ and t4, girls consumed more fruits than boys, and there was no significant grade effects $(p=$ 0.136), but significant time effects ( $p<0.001)$, and interaction effects between time and grade $(p=0.049)$ on the previous day fruits consumption. In other words, the effects of intervention depended on which grade were the children in. The results of ANOVA indicated that at $\mathrm{t} 1$, students in Grade 4 consumed more fruits than students in Grade 3 (1.24 vs. $0.93, p=0.048)$.

\section{Vegetables Consumption}

The between subject tests indicated that there were significant school effects $(p<$ $0.001)$, but no significant age effects $(p=0.994)$ on the previous day vegetables consumption. The results of linear regression indicated that only at baseline, the previous day vegetables consumption significantly increased with age $(\hat{\beta}=0.067, p=0.009)$.

From baseline to 4 , the effects of intervention on the previous day vegetables consumption were significantly different among the four schools. Children in School 1 consumed more vegetables than children in other schools. The within subject test indicated that there were significant intervention effects $(p<0.001)$, interaction effects between time and school $(p<0.001)$, and interaction effects between time and age $(p=$ 
0.014) on the previous day vegetables consumption. That is, the effects of intervention depended on which school were the children in and the age of the children.

There was significant sex effects $(p=0.008)$ and time effects $(p<0.001)$, but no significant interaction effects between time and sex $(p=0.358)$ on the previous day vegetables consumption. Specifically, at $\mathrm{t} 2, \mathrm{t} 3$, and $\mathrm{t} 4$, girls consumed more vegetables than boys. The between subject tests indicated that there was no significant grade effects $(p=0.873)$ on the previous day vegetables consumption. The results of ANOVA indicated that at $\mathrm{t} 1$, children in Grade 1 consumed more vegetables than children in Grade 3 (3.14 vs. $2.30, p=0.025)$. The within subject test indicated that there were significant time effects $(p<0.001)$, and interaction effects between time and grade $(p<0.001)$ on the previous day vegetables consumption. In other words, the effects of intervention depended on which grade were the students in.

\section{Comparison of Statistical Models}

When using Mauchly's test to examine sphericity, the $p$-values for all models were less than 0.05 , indicating that the sphericity assumption for multiple-sample repeated measures ANOVA did not hold. Thus, multiple-sample repeated measures ANOVA was not suitable for analyzing this data set. Through comparing the statistical models (with random intercept and slope) using different variance-covariance structures (See Table 7), models using the compound symmetry structures did not fit the data well. Moreover, the mixed-effects regression models using unstructured or autoregressive heterogeneous variances structure had smallest AIC values and the -2 Log Likelihood scores were significantly smaller than the -2 Log Likelihood scores of other models, 
suggesting that the variance-covariance structure fitting the data well had heterogeneous variances. 
Table 7

Model comparisons (comparing to multiple-sample repeated measures ANOVA using compound symmetry)

\begin{tabular}{|c|c|c|c|c|c|c|}
\hline Model & AIC & $-2 R L L$ & $\begin{array}{l}\text { Parameters } \\
\qquad(d f+1)\end{array}$ & $\begin{array}{c}\text { Diff }-2 \text { RLL } \\
\text { (vs. CS })\end{array}$ & $\begin{array}{l}\text { Diff in df } \\
\text { (vs. CS) }\end{array}$ & $\begin{array}{l}p \text {-value for Diff } \\
\text { (chi square dist.) }\end{array}$ \\
\hline
\end{tabular}

$\underline{\text { Pedometer }=\text { grade }+ \text { time }+ \text { grade } * \text { time }}$

Compound Symmetry

Unstructured

Autoregressive

$\begin{array}{lll}140568.9 & 140572.9 & 2\end{array}$

Autoregressive Heterogeneous Variances

$140382.9 \quad 140390.9$

$140568.9 \quad 140572.9$

$140382.9 \quad 140390.9$

0
182

$<0.001$

na

2

$\begin{array}{lll}139446.4 & 139450.4 & 2 \\ 139237.4 & 139245.4 & 4 \\ 139446.4 & 139450.4 & 2 \\ 139237.4 & 139245.4 & 4\end{array}$

205
0
205

$<0.001$

na

Autoregressive

205

$<0.001$

$\underline{\text { Pedometer }=\text { school }+ \text { age }+ \text { time }+ \text { school } * \text { time }}$

\section{Compound Symmetry}

Unstructured

Autoregressive

Autoregressive Heterogeneous Variances

$\begin{array}{lll}139334.7 & 139330.7 & 2 \\ 139144.0 & 139138.0 & 3 \\ 139334.7 & 139330.7 & 2 \\ 139144.3 & 139138.3 & 3\end{array}$

192.7
0
192.4

1

0

$<0.001$

na

$<0.001$ 
$\underline{\text { Eating Behavior }=\text { grade }+ \text { time }+ \text { grade } * \text { time }+ \text { time } * \text { time }}$

Compound Symmetry 41720.7

Unstructured

41463.6

41724.7

41720.7

41463.6

Autoregressive

41724.7

Autoregressive Heterogeneous Variances

41463.6

41463.6

261.1

0

261.1

0.001

na

$<0.001$

$\underline{\text { Eating Behavior }=\operatorname{sex}+\text { time }+ \text { sex } * \text { time }+ \text { time*time }}$

Compound Symmetry

Unstructured

Autoregressive

Autoregressive Heterogeneous Variances

$\begin{array}{lll}41343.0 & 41347.0 & 2 \\ 41085.6 & 41093.6 & 4 \\ 41343.0 & 41347.0 & 2 \\ 41085.6 & 41093.6 & 4\end{array}$

253.4

2

$<0.001$

0

253.4

na

$<0.001$

Eating Behavior $=$ school + age + time + school $*$ time + time $*$ time

Compound Symmetry

Unstructured

Autoregressive

Autoregressive Heterogeneous Variances $\begin{array}{lll}41162.8 & 41162.8 & 2\end{array}$

$41002.0 \quad 41010.0 \quad 4$

$\begin{array}{lll}41162.8 & 41162.8 & 2\end{array}$

$\begin{array}{lll}41162.8 & 41162.8 & 2 \\ 41002.0 & 41010.0 & 4\end{array}$

$\begin{array}{ccc}152.8 & 2 & <0.001 \\ 0 & 0 & \text { na } \\ 152.8 & 2 & <0.001\end{array}$




\section{CHAPTER 5}

\section{SUMMARY, DISCUSSION, AND CONCLUSIONS}

This chapter summarizes the results of this study, discusses the findings related to literature and directions for future studies, and explains the strengths and limitations. In addition, a brief conclusion is presented to summarize the findings of this study.

\section{Summary}

Childhood obesity has become a public health crisis in U.S. Kentucky has the second highest rate of childhood obesity in America. In 2007, 37\% of children were overweight or obese in Kentucky compared to $32 \%$ of children across the nation (Foundation for a Healthy Kentucky, 2009). Further, the majority of Kentuckians thought childhood obesity was a serious problem influencing children's health and increasing the nation's health care costs. Concerning the childhood obesity epidemic, $87 \%$ of Kentucky adults favored for schools to provide 30 minutes physical activity or physical education to students per day (Foundation for a Healthy Kentucky, 2009). However, the state law of Kentucky does not require schools to provide physical education for all grades (K-12) (Kaiser Family Foundation, 2011). In addition, evidence has shown that children from low socioeconomic class were less likely to have physical education in their schools (Lewis, 2007). Thus, healthy lifestyle programs among children from low socioeconomic class in Kentucky are urgently needed.

This study presented a comprehensive, school-based, healthy lifestyle program for children. The design of the program was based on the Coordinated School Health Model 
recommendation of the CDC. All children from kindergarten to $5^{\text {th }}$ grade in four rural elementary schools of Kentucky participated in this program. A variety of strategies were integrated in the daily routine of schools to obtain four goals: (1) improving physical activity level, (2) improving health and nutrition education (U.S. Department of Health and Human Services, 2012), (3) promoting family/community involvement through Family Fitness Fun Nights, and (4) realigning school's wellness policy with HealthierUS School Challenge (U.S. Department of Agriculture, 2011b). Two measurements (physical activity level and previous day fruits and vegetables consumption) were used to assess the effects of this program.

A total of 1,508 children participated in the healthy lifestyle program in the first year. During this time, the percentages of children meeting physical activity and fruits and vegetables consumption recommendation increased significantly. From baseline to t4, physical activity level was positively correlated with children's age. In other words, older children participated in higher level of physical activity. The fruits and vegetables consumption was positively correlated with children's age only at Baseline. Boys participated in higher level of physical activity while girls consumed more fruits and vegetables. Overall, this healthy lifestyle program had significant effects on improving children's physical activity level and fruits and vegetables consumption. The increasing linear trends of physical activity level over time were unequal among the four schools. Physical activity level increased faster in School 3, and increased slower in School 4. Similarly, the increasing trends of fruits and vegetables consumption were unequal among the four schools, and fruits and vegetables consumption increased slower in School 4. The effects of this program on physical activity level and previous day fruits 
and vegetables consumption depended on which school, grade and the age of the children. In all, children's physical activity level increased by 273.8 steps per month, and their previous day fruits and vegetables consumption increased by 1.03 fruit or vegetable per month.

\section{Discussion}

In this study, at baseline, only $1.6 \%$ of girls and $1.1 \%$ of boys met the physical activity recommendation - participating in at least 60 minutes moderate- or vigorousintensity physical activity per day. Similarly, only $15 \%$ of children in this study consumed three or more servings of vegetables and two or more servings of fruits per day. However, one study in two Midwestern communities found that $41.3 \%$ of boys and $45.6 \%$ of girls met the physical activity recommendation (Laurson et al., 2008), which is much higher than the percentages found in this study. National data suggests that on average, $48 \%$ of boys and $35 \%$ of girls participate in at least 60 minutes physical activity per day (Troiano et al., 2008), and $21 \%$ of children have the recommended five or more servings of fruits and vegetables each day (Slyper, 2004). However, no statewide or national study has been found to assess the percentages of Kentuckian children meeting physical activity and nutrition recommendation. Thus, national research is needed to assess the percentages of children meeting physical activity and nutrition recommendations across state.

The reason for the low percentages of children meeting physical activity and nutrition recommendations may be attributed to the study setting and socioeconomic status of the subjects. Subjects in this study were recruited from a rural district, and about $69 \%$ of the children were eligible for free lunch or reduced-price lunch (National Center 
for Educational Statistics, 2012). In addition, evidence has supported that rural residency is a risk factor for children being overweight or obese and participating in unhealthy behaviors - sedentary activity and sugar/fat consumption (Liu et al., 2008; Lutfiyya et al., 2007). The low percentages of rural children meeting physical activity and nutrition recommendations suggest that further healthy lifestyle programs need to tailor rural children for improving healthy behaviors and finally preventing or controlling childhood obesity.

Findings from this study suggest that the program had significant effects on improving the percentages of children meeting physical activity and nutrition recommendations, and increasing physical activity level and improving eating behavior over time. In response to the childhood obesity epidemic, many family-based and schoolbased healthy lifestyle programs have been designed and conducted to improve children's healthy behaviors and control the childhood obesity epidemic. Family-based healthy lifestyle programs have been supported to have effects on reducing BMI, and increasing physical activity and healthy eating behaviors (Brotman et al., 2012; Sacher et al., 2010). Similarly, school-based healthy lifestyle programs have significant effects on decreasing abdominal obesity, sedentary activity and snacks consumption, and increasing vegetable consumption and physical activity (Bacardi-Gascon et al., 2012; Greening et al., 2011).

Evidence shows strong public support for school-based healthy lifestyle programs aimed at controlling overweight and obesity among children. The majority of Americans favored school-based interventions such as teaching students healthy eating and exercise habits in school, requiring more physical education classes, recess and supervised intramural activities, restricting unhealthy foods and drinks in school vending machines 
and school cafeterias, and providing exercise programs for obese children (Evans et al., 2005). Similarly, the majority of Kentucky adults would love schools to provide physical activity programs to students (Foundation for a Healthy Kentucky, 2009). In addition, a comprehensive intervention in elementary schools including a classroom curriculum, a physical education program, modifications to the school food services and family-based programs, is supported to be highly cost-effective compared to other programs among adolescents or adults (H. S. Brown et al., 2007; Cawley, 2010). Therefore, comprehensive school-based programs in elementary schools are a public supportive and cost-effective way to prevent and control childhood obesity. Moreover, the effectiveness of the program on improving children's physical activity and eating behavior supports that the Coordinated School Health Program (CSHP) can be successfully integrated into children's routine school life, and has the promising role in promoting healthy lifestyle and controlling childhood obesity.

This study found that the physical activity and eating behavior change trends over time were similar between boys and girls, which was also supported by other studies (Greening et al., 2011). In other words, school-based healthy lifestyle programs do not have different effects based on sex, though boys participated in higher level of physical activity while girls consumed more fruits and vegetables. Moreover, the effects of the program on healthy behaviors depended on which school, grade, or the age of the children, suggesting that further school-based healthy lifestyle programs need to be tailored to the individual needs and contexts of children.

For School 4, the Family Fitness Fun Night was cancelled due to time constraints in the school year. Children in School 4 were older than children from other schools, 
based on the findings that physical activity level was positively correlated with the age of children, children in School 4 should participate in higher level of physical activity. However, children in School 4 participated in the lowest level of physical activity since t3, and their physical activity level increased slowly over time. Similarly, children in School 4 consumed the fewest fuits and vegetables since $t 2$, and their fruits and vegetables consumption increased slowly over time. Thus, Family Fitness Fun Night may be an indispensable component that the healthy lifestyle program should include. From another point of view, these findings reflect the important roles that family and community play in the promotion of healthy lifestyle among children. In other words, the support of family and community are necessary in controlling the childhood obesity epidemic (J. E. Williams, 2011).

Findings from this study also suggest that school-based healthy lifestyle interventions, integrated into children's daily routine of schools, have the potential to promote healthy behaviors among children. Schools are an ideal setting for healthy lifestyle promotion programs. School officials should consider incorporating nutrition, physical activity and health messages into school curriculum and aligning school wellness policies with the HealthierUS School Challenge criteria. Classroom teachers can play a vital role in helping children adopt healthy lifestyles in school. In addition, schools should collaborate with community and family to obtain resources, conduct healthy lifestyle programs, control childhood obesity, and improve children's health. Results from school-based interventions should be shared with school officials, classroom teachers, health educators, school health scientists and policy makers for further intervention design, conduct and policy change. 
Results from this study indicates that the two most promising variance-covariance structures were unstructured and autoregressive heterogeneous variances since they had smallest AIC values and the -2 Log Likelihood scores were significantly smaller than those of other models, suggesting that the variance-covariance structure of the data did not meet the assumption of sphericity. In other words, multiple-sample repeated measures ANOVA was not suitable in analyzing the data. Mixed-effects regression models are robust to the assumption of sphericity, and can fit different covariance patterns leading more appropriate fixed effects estimates (H. Brown \& Prescott, 2006). Moreover, they can deal with missing data easily without deleting cases with missing data, and they can be applied to the repeated measures data with unequal time intervals. Thus, further studies are needed to explore the efficacy of mixed-effects regression models in analyzing repeated measures data compared to univariate repeated measures ANOVA.

\section{Limitations}

Several limitations existed in the study. Quasi-experimental design (intervention group only) places the findings from this study in an untenable position compared to the randomly controlled trial. Due to the lack of a control group, the effects of the intervention may attribute to confounding factors - policy, media or environment. Another limitation is the lack of control of other factors such as socioeconomic status, parents' education level, marital status, employment status and ethnicity, because only the information related to sex, age, grade and school was collected due to the requirement of the school system. Moreover, the consumption of fruits and vegetables was assessed by a self-reported food frequency questionnaire instead of a weighed dietary record. The 
BMI, waist circumstance, skin fold or other obesity indices were not applied to evaluate the effects of this program on controlling childhood obesity.

Although there were several limitations in this study, the relatively large-scale study including 1,508 students provided useful information related to the level of physical activity and eating behaviors in this group of rural children from Kentucky. Other strengths included the objective measurement of physical activity level and the reliable scale assessing eating behavior that allowed the results from this study to be generalizable to all rural children in Kentucky. The intervention was easily integrated in the daily routine of schools, which has the potential to act as a model for future schoolbased program design. In addition, advanced data analysis techniques, especially mixedeffects regression models, were used to manage the data, which provided clear, concise and strong scientific evidence of the effects of the intervention on improving healthy behaviors.

\section{Conclusions}

Children in this study participated in lower level of physical activity and consumed fewer fruits and vegetables than those reported in other national surveyed samples. Boys in this study participated in higher level of physical activity while consumed fewer fruits and vegetables. For children in these elementary schools, their physical activity level increased as they aged. The comprehensive school-based intervention had beneficial effects on improving healthy behaviors among children. Results from this study support the feasibility of the Coordinated School Health Program recommended by CDC conducted in school system and the effects on improving children's healthy behaviors in school. However, the data argues in favor of further 
studies on evaluating the long-term effects on improving healthy behaviors, and the costeffectiveness of this program using the societal method.

Results from this study indicate that school-based healthy lifestyle programs should involve the support and resources from community and family. The American Academy of Pediatrics (AAP) recommends that healthy lifestyle promotion programs should focus on habit forming rather than short-term behavior change (McCambridge et al., 2006), thus, further studies are needed to assess its life-long effects on habit forming. Moreover, future researches are needed to examine the effects of the intervention on controlling childhood obesity and its cost-effectiveness, and test its effects in other contexts, such as in urban areas, other ethnic groups, etc. 


\section{REFERENCES}

Agresti, A. (2007). An introduction to categorical data analysis. New Jersey: John Wiley $\&$ Sons, Inc.

Alliance for a Healthier Generation. (2011). State report: Progress in the healthy schools program. Retrieved July 15, 2012, from http://www.healthiergeneration.org/uploadedfiles/For_Schools/StateReports/101938.pdf

American Heart Association. (2012). Statistical fact sheet 2012 update: Overweight \& obesity. Retrieved July 15, 2012, from http://www.heart.org/idc/groups/heartpublic/@wcm/@sop/@smd/documents/downloadable/ucm_319588.pdf

Bacardi-Gascon, M., Perez-Morales, M. E., \& Jimenez-Cruz, A. (2012). A six month randomized school intervention and an 18-month follow-up intervention to prevent childhood obesity in Mexican elementary schools. Nutricion Hospitalaria, 27(3), 755-762. doi: DOI 10.3305/nh.2012.27.3.5756

Bellamy, G. R., Bolin, J. N., \& Gamm, L. D. (2011). Rural Healthy People 2010, 2020, and beyond the need goes on. Family \& Community Health, 34(2), 182-188. doi: Doi 10.1097/Fch.0b013e31820dea1c

Blackwell, E., de Leon, C. F. M., \& Miller, G. E. (2006). Applying mixed regression models to the analysis of repeated-measures data in psychosomatic medicine. Psychosomatic Medicine, 68(6), 870-878. 
Bock, R., \& Miller, M. G. (2008). Children's physical activity drops from age 9 to 15, NIH study indicates. Retrieved August 15, 2012, from http://www.nih.gov/news/health/jul2008/nichd-15.htm

Bowman, S. A., Gortmaker, S. L., Ebbeling, C. B., Pereira, M. A., \& Ludwig, D. S. (2004). Effects of fast-food consumption on energy intake and diet quality among children in a national household survey. Pediatrics, 113(1), 112-118.

Brotman, L. M., Dawson-McClure, S., Huang, K. Y., Theise, R., Kamboukos, D., Wang, J., . . Ogedegbe, G. (2012). Early childhood family intervention and long-term obesity prevention among high-risk minority youth. Pediatrics, 129(3), E621E628. doi: DOI 10.1542/peds.2011-1568

Brown, H., \& Prescott, R. (2006). Applied mixed models in Medicine. The Atrium, Southern Gate, Chichester, West Sussex: John Wiley \& Sons, Ltd.

Brown, H. S., Perez, A., Li, Y. P., Hoelscher, D. M., Kelder, S. H., \& Rivera, R. (2007). The cost-effectiveness of a school-based overweight program. International Journal of Behavioral Nutrition and Physical Activity, 4, 47. doi: Artn 47 Doi $10.1186 / 1479-5868-4-47$

Bukara-Radujkovic, G., \& Zdravkovic, D. (2009). Physical activity as an important determinant in developing childhood obesity. Med Pregl, 62(3-4), 107-113.

Caspersen, C. J., Powell, K. E., \& Christenson, G. M. (1985). Physical activity, exercise, and physical fitness: Definitions and distinctions for health-related research. Public Health Reports (Washington, D C : 1974), 100(2), 126-131.

Cawley, J. (2010). The economics of childhood obesity. Health Affairs, 29(3), 364-371. doi: DOI 10.1377/hlthaff.2009.0721 
Cawley, J., Rizzo, J. A., \& Haas, K. (2007). Occupation-specific absenteeism costs associated with obesity and morbid obesity. Journal of Occupational and Environmental Medicine, 49(12), 1317-1324. doi: Doi

10.1097/Jom.0b013e31815b56a0

Center for the Advancement of Physical Education. (2004). Our nations' broken physical education system: Why it needs to be fixed, and how we can do it together. Retrieved August 15, 2012, from http://www.pe4life.org/UserFiles/File/Blueprint_Version_2(1).pdf

Centers for Disease Control and Prevention. (2004). Participation in high school physical education-United States, 1991-2003. Retrieved July 15, 2012, from http://www.cdc.gov/mmwr/preview/mmwrhtml/mm5336a5.htm

Centers for Disease Control and Prevention. (2010). Youth online: High school YRBS Kentucky 2009 and United States 2009 results. Retrieved July 15, 2012, from http://www.cdc.gov/healthyyouth/yrbs/factsheets/index.htm\#compare

Centers for Disease Control and Prevention. (2011a). About BMI for children and teens. Retrieved July 15, 2012, from http://www.cdc.gov/healthyweight/assessing/bmi/childrens_bmi/about_childrens_ bmi.html

Centers for Disease Control and Prevention. (2011b). Children (Approximate Ages 4-11). Retrieved November 13, 2012, from http://www.cdc.gov/parents/children/index.html

Centers for Disease Control and Prevention. (2011c). Coordinated school health. Retrieved August 15, 2012, from http://www.cdc.gov/HealthyYouth/CSHP/ 
Centers for Disease Control and Prevention. (2011d). How much physical activity do children need? Retrieved November 13, 2012, from http://www.cdc.gov/physicalactivity/everyone/guidelines/children.html Centers for Disease Control and Prevention. (2011e). National Health Education Standards. Retrieved September 02, 2012, from http://www.cdc.gov/healthyyouth/SHER/standards/index.htm

Centers for Disease Control and Prevention. (2011f). Overweight and obesity. Retrieved November 13, 2012, from http://www.cdc.gov/obesity/childhood/basics.html Chen, E., \& Matthews, K. A. (2002). Socioeconomic differences in children's health: How and why do these relationships change with age? Psychological Bulletin, 128(2), 295-329. doi: Doi 10.1037/0033-2909.128.2.295

Cherry, D. C., Huggins, B., \& Gilmore, K. (2007). Children's health in the rural environment. Pediatric Clinics of North America, 54(1), 121-133. doi: DOI 10.1016/j.pcl.2006.11.008

Crespo, C. J., Smit, E., Troiano, R. P., Bartlett, S. J., Macera, C. A., \& Andersen, R. E. (2001). Television watching, energy intake, and obesity in US children: Results from the third National Health and Nutrition Examination Survey, 1988-1994. Archives of Pediatrics \& Adolescent Medicine, 155(3), 360-365.

Dalziel, K., \& Segal, L. (2006). Point: Uncertainty in the economic analysis of schoolbased obesity prevention programs: Urgent need for quality evaluation. Obesity, 14(9), 1481-1482. 
Datar, A., Sturm, R., \& Magnabosco, J. L. (2004). Childhood overweight and academic performance: National study of kindergartners and first-graders. Obesity Research, 12(1), 58-68.

Davis, M. M., Gance-Cleveland, B., Hassink, S., Johnson, R., Paradis, G., \& Resnicow, K. (2007). Recommendations for prevention of childhood obesity. Pediatrics, 120, S229-S253. doi: DOI 10.1542/peds.2007-2329E

Duke, J., \& Huhman, M. (2003). Physical activity levels among children aged 9 - 13 years - United States, 2002. MMWR, 52(33), 785-788.

Evans, W. D., Finkelstein, E. A., Kamerow, D. B., \& Renaud, J. M. (2005). Public perceptions of childhood obesity. American Journal of Preventive Medicine, 28(1), 26-32. doi: DOI 10.1016/j.amepre.2004.09.008

Foundation for a Healthy Kentucky. (2009). Kentucky health issues poll: What Kentuckians think about childhood obesity. Retrieved August 31, 2012, from https://www.healthfoundation.org/docs/What\%20Kentuckians\%20Think\%20abou t\%20Childhood\%20Obesity.pdf

Ganz, M. L. (2003). The economic evaluation of obesity interventions: Its time has come. Obesity Research, 11(11), 1275-1277.

Gates, D. M., Succop, P., Brehm, B. J., Gillespie, G. L., \& Sommers, B. D. (2008). Obesity and presenteeism: The impact of body mass index on workplace productivity. Journal of Occupational and Environmental Medicine, 50(1), 39-45. doi: Doi 10.1097/Jom.0b013e31815d8db2

Goran, M. I., \& Treuth, M. S. (2001). Energy expenditure, physical activity, and obesity in children. Pediatric clinics of North America, 48(4), 931-953. 
Gray, R., \& Francis, E. (2007). The implications of US experiences with early childhood interventions for the UK Sure Start Programme. Child: Care, Health and Development, 33(6), 655-663.

Greening, L., Harrell, K. T., Low, A. K., \& Fielder, C. E. (2011). Efficacy of a schoolbased childhood obesity intervention program in a rural southern community: TEAM Mississippi Project. Obesity, 19(6), 1213-1219. doi: Doi 10.1038/Oby.2010.329

Hedeker, D., \& Gibbons, R. D. (2006). Longitudinal data analysis. New Jersey: John Wiley \& Sons, Inc.

Hills, A. P., Andersen, L. B., \& Byrne, N. M. (2011). Physical activity and obesity in children. British Journal of Sports Medicine, 45(11), 866-870. doi: 10.1136/bjsports-2011-090199

Hills, A. P., King, N. A., \& Armstrong, T. P. (2007). The contribution of physical activity and sedentary behaviours to the growth and development of children and adolescents: Implications for overweight and obesity. Sports Medicine, 37(6), $533-545$.

Janssen, I., Katzmarzyk, P. T., Boyce, W. F., Vereecken, C., Mulvihill, C., Roberts, C., ... Grp, Hlth Behav School-Aged Children Obes Working. (2005).

Comparison of overweight and obesity prevalence in school-aged youth from 34 countries and their relationships with physical activity and dietary patterns. Obesity Reviews, 6(2), 123-132. 
Judge, S., \& Jahns, L. (2007). Association of overweight with academic performance and social and behavioral problems: An update from the early childhood longitudinal study. The Journal of School Health, 77(10), 672-678.

Kaiser Family Foundation. (2011). Kentucky: State laws addressing childhood obesity. Retrieved August 31, 2012, from http://www.statehealthfacts.org/profileind.jsp?ind=52\&cat=2\&rgn=19

Kelly, K. P., \& Kirschenbaum, D. S. (2011). Immersion treatment of childhood and adolescent obesity: The first review of a promising intervention. Obesity Reviews, 12(1), 37-49. doi: DOI 10.1111/j.1467-789X.2009.00710.x

Kentucky Department of Education. (2012). Coordinated school health. Retrieved July 15,2012 , from http://www.education.ky.gov/kde/administrative+resources/coordinated+school+h ealth/

Kincaid, C., \& COMSYS Information Technology Services. (2005). Guidelines for selecting the covariance structure in mixed model analysis. Statistics and Data Analysis. LC.GC. Europe Online Supplement, Paper 198-30.

Kirk, S., Scott, B. J., \& Daniels, S. R. (2005). Pediatric obesity epidemic: Treatment options. Journal of the American Dietetic Association, 105(5), S44-S51. doi: DOI 10.1016/j.jada.2005.02.013

Kutner, M. H., Nachtsheim, C. J., Neter, J., \& Li, W. (2005). Applied linear statistical models. New York: McGraw-Hill/Irwin.

Laurson, K. R., Eisenmann, J. C., Welk, G. J., Wickel, E. E., Gentile, D. A., \& Walsh, D. A. (2008). Evaluation of youth pedometer-determined physical activity guidelines 
using receiver operator characteristic curves. Preventive Medicine, 46(5), 419424. doi: DOI 10.1016/j.ypmed.2007.12.017

Lee, S. M., Burgeson, C. R., Fulton, J. E., \& Spain, C. G. (2007). Physical education and physical activity: Results from the school health policies and programs study 2006. Journal of School Health, 77(8), 435-463.

Li, Y. F., Dai, Q., Jackson, J. C., \& Zhang, J. (2008). Overweight is associated with decreased cognitive functioning among school-age children and adolescents. Obesity, 16(8), 1809-1815. doi: Doi 10.1038/Oby.2008.296

Liu, J. H., Bennett, K. J., Harun, N., \& Probst, J. C. (2008). Urban-rural differences in overweight status and physical inactivity among US children aged 10-17 years. Journal of Rural Health, 24(4), 407-415.

Liu, J. H., Jones, S. J., Sun, H., Probst, J., Merchant, A., \& Cavicchia, P. (2010). Diet, physical activity, and sedentary behaviors as risk factors for childhood obesity: An urban and rural comparison. Obesity, 18, S178-S178.

Lobstein, T., Baur, L., Uauy, R., \& Iaso International Obesity TaskForce. (2004). Obesity in children and young people: A crisis in public health. Obesity Reviews(5 Suppl 1), 4-104.

Ludwig, D. S., Peterson, K. E., \& Gortmaker, S. L. (2001). Relation between consumption of sugar-sweetened drinks and childhood obesity: A prospective, observational analysis. Lancet, 357(9255), 505-508.

Lutfiyya, M. N., Lipsky, M. S., Wisdom-Behounek, J., \& Inpanbutr-Martinkus, M. (2007). Is rural residency a risk factor for overweight and obesity for US children? Obesity, 15(9), 2348-2356. 
Marshall, S. J., Gorely, T., \& Biddle, S. J. H. (2006). A descriptive epidemiology of screen-based media use in youth: A review and critique. Journal of Adolescence, 29(3), 333-349. doi: DOI 10.1016/j.adolescence.2005.08.016

McAuley, K. A., Taylor, R. W., Farmer, V. L., Hansen, P., Williams, S. M., Booker, C. S., \& Mann, J. I. (2010). Economic evaluation of a community-based obesity prevention program in children: The APPLE project. Obesity, 18(1), 131-136.

McCambridge, T. M., Bernhardt, D. T., Brenner, J. S., Congeni, J. A., Gomez, J. E., Gregory, A. J. M., . . Hlth, Council School. (2006). Active healthy living: Prevention of childhood obesity through increased physical activity. Pediatrics, 117(5), 1834-1842. doi: DOI 10.1542/peds.2006-0472

National Center for Educational Statistics. (2012). Search for public schools. Retrieved January 24, 2013, from http://nces.ed.gov/ccd/schoolsearch/

Norusis, M. J. (2010). PASW statistics 18: Guide to data analysis. NJ, Upper Saddle River: Prentice Hall Inc.

Nowicka, P., \& Flodmark, C. E. (2007). Physical activity-key issues in treatment of childhood obesity. Acta Paediatrica Supplement, 96(454), 39-45. doi: 10.1111/j.1651-2227.2007.00169.x

Ogden, C. (2010). Prevalence of obesity among children and adolescents: United States, trends 1963-1965 through 2007-2008. Retrieved August 15, 2012, from http://www.cdc.gov/nchs/data/hestat/obesity_child_07_08/obesity_child_07_08.ht $\mathrm{m}$ 
Olshansky, S. J., Passaro, D. J., Hershow, R. C., Layden, J., Carnes, B. A., Brody, J., . . . Ludwig, D. S. (2005). A potential decline in life expectancy in the United States in the 21st century. The New England Journal of Medicine, 352(11), 1138-1145.

Orlet, F. J., Rolls, B. J., \& Birch, L. L. (2003). Children's bite size and intake of an entree are greater with large portions than with age-appropriate or self-selected portions. The American Journal of Clinical Nutrition, 77(5), 1164-1170.

Paeratakul, S., Ferdinand, D. P., Champagne, C. M., Ryan, D. H., \& Bray, G. A. (2003). Fast-food consumption among US adults and children: Dietary and nutrient intake profile. Journal of the American Dietetic Association, 103(10), 1332-1338. doi: Doi 10.1053/S0002-8223(03)01086-1

Pedan, A. (n.d.). Smoothing with SAS PROC MIXED. Statistics and Data Analysis. Retrieved March 04, 2013, from www2.sas.com/proceedings/sugi28/268-28.pdf

Penkilo, M., George, G. C., \& Hoelscher, D. M. (2008). Reproducibility of the SchoolBased Nutrition Monitoring Questionnaire among fourth-grade students in Texas. Journal of Nutrition Education and Behavior, 40(1), 20-27.

Plachta-Danielzik, S., Landsberg, B., Lange, D., Seiberl, J., \& Muller, M. J. (2011). Eight-year follow-Up of school-based intervention on childhood overweight - the Kiel obesity prevention study. Obesity Facts, 4(1), 35-43. doi: Doi $10.1159 / 000324552$

Reilly, J. J. (2005). Descriptive epidemiology and health consequences of childhood obesity. Best Practice \& Research Clinical Endocrinology \& Metabolism, 19(3), $327-341$. 
Reilly, J. J., Methven, E., McDowell, Z. C., Hacking, B., Alexander, D., Stewart, L., \& Kelnar, C. J. H. (2003). Health consequences of obesity. Archives of Disease in Childhood, 88(9), 748-752.

Rowland, T. W. (2007). Promoting physical activity for children's health: Rationale and strategies. Sports Medicine, 37(11), 929-936.

Sacher, P. M., Kolotourou, M., Chadwick, P. M., Cole, T. J., Lawson, M. S., Lucas, A., \& Singhal, A. (2010). Randomized controlled trial of the MEND program: A family-based community intervention for childhood obesity. Obesity, 18, S62S68. doi: Doi 10.1038/Oby.2009.433

School Nutrition Association. (2011). Implementing the Healthy, Hunger-Free Kids Act. Retrieved July 15, 2012, from http://www.schoolnutrition.org/Blog.aspx?id=15349\&blogid=622

Siegrist, M., Hanssen, H., Lammel, C., Haller, B., \& Halle, M. (2011). A cluster randomised school-based lifestyle intervention programme for the prevention of childhood obesity and related early cardiovascular disease (JuvenTUM 3). BMC Public Health, 11. doi: Artn 258 Doi 10.1186/1471-2458-11-258

Skinner, J. D., Bounds, W., Carruth, B. R., Morris, M., \& Ziegler, P. (2004). Predictors of children's body mass index: A longitudinal study of diet and growth in children aged 2-8 y. International Journal of Obesity and Related Metabolic Disorders, 28(4), 476-482. doi: 10.1038/sj.ijo.0802405

Skinner, J. D., Bounds, W., Carruth, B. R., \& Ziegler, P. (2003). Longitudinal calcium intake is negatively related to children's body fat indexes. Journal of the American 
Dietetic Association, 103(12), 1626-1631. doi: Doi 10.1016/S00028223(03)01361-0

Slyper, A. H. (2004). The pediatric obesity epidemic: Causes and controversies. Journal of Clinical Endocrinology \& Metabolism, 89(6), 2540-2547. doi: DOI $10.1210 /$ jc.2003-031449

SPARK. (2012). Physical education. Retrieved November 13, 2012, from http://www.sparkpe.org/physical-education/

Steinbeck, K. S. (2001). The importance of physical activity in the prevention of overweight and obesity in childhood: A review and an opinion. Obesity Reviews, 2(2), 117-130.

Stevens, J. P. (2009). Applied multivariate statistics for the social sciences. New York: Taylor \& Francis Group, LLC.

Stokes, M. E., Davis, C. S., \& Koch, G. G. (2000). Categorical data analysis using the SAS system. Cary, NC: SAS Institute Inc.

Strauss, R. S. (2000). Childhood obesity and self-esteem. Pediatrics, 105(1), e15.

Subar, A. F., Krebs-Smith, S. M., Cook, A., \& Kahle, L. L. (1998). Dietary sources of nutrients among US children, 1989-1991. Pediatrics, 102(4 Pt 1), 913-923.

Taras, H., \& Potts-Datema, W. (2005). Obesity and student performance at school. Journal of School Health, 75(8), 291-295.

The White House: Office of the Press Secretary. (2010). President Obama Signs Healthy, Hunger-Free Kids Act of 2010 Into Law. Retrieved July 15, 2012, from http://www.whitehouse.gov/the-press-office/2010/12/13/president-obama-signshealthy-hunger-free-kids-act-2010-law 
Thiagarajah, K., Fly, A. D., Hoelscher, D. M., Bai, Y., Lo, K., Leone, A., \& Shertzer, J. A. (2008). Validating the food behavior questions from the elementary school SPAN questionnaire. Journal of Nutrition Education and Behavior, 40(5), 305310.

Thompson, O. M., Ballew, C., Resnicow, K., Must, A., Bandini, L. G., Cyr, H., \& Dietz, W. H. (2004). Food purchased away from home as a predictor of change in BMI Z-score among girls. International Journal of Obesity, 28(2), 282-289. doi: DOI 10.1038/sj.ijo.0802538

Trasande, L., \& Chatterjee, S. (2009). The impact of obesity on health service utilization and costs in childhood. Obesity, 17(9), 1749-1754. doi: Doi 10.1038/Oby.2009.67

Trasande, L., Liu, Y. H., Fryer, G., \& Weitzman, M. (2009). Effects of childhood obesity on hospital care and costs, 1999-2005. Health Affairs, 28(4), W751-W760. doi: DOI 10.1377/hlthaff.28.4.w751

Troiano, R. P., Berrigan, D., Dodd, K. W., Masse, L. C., Tilert, T., \& McDowell, M. (2008). Physical activity in the United States measured by accelerometer. Medicine and Science in Sports and Exercise, 40(1), 181-188. doi: 10.1249/mss.0b013e31815a51b3

Tudor-Locke, C., Craig, C. L., Beets, M. W., Belton, S., Cardon, G. M., Duncan, S., . . . Blair, S. N. (2011). How many steps/day are enough? for children and adolescents. International Journal of Behavioral Nutrition and Physical Activity, 8, 78. doi: Artn 78 Doi 10.1186/1479-5868-8-78 
Tudor-Locke, C., Hatano, Y., Pangrazi, R. P., \& Kang, M. (2008). Revisiting "how many steps are enough?". Medicine and Science in Sports and Exercise, 40(7), S537S543. doi: Doi 10.1249/Mss.0b013e31817c7133

U.S. Department of Agriculture. (2011a). Dietary guidelines for American. Retrieved July 15, 2012, from http://www.cnpp.usda.gov/DGAs2010-PolicyDocument.htm U.S. Department of Agriculture. (2011b). HealthierUS School Challenge. Retrieved November 10, 2012, from http://teamnutrition.usda.gov/healthierUS/index.html U.S. Department of Health \& Human Services. (2012). Childhood obesity. Retrieved July 15, 2012, from http://www.health.gov/

U.S. Department of Health and Human Services. (2012). Physical activity guidelines and dietary guidelines. Retrieved December 27, 2012, from http://www.health.gov/

Veldwijk, J., Fries, M. C. E., Bemelmans, W. J. E., Haveman-Nies, A., Smit, H. A., Koppelman, G. H., \& Wijga, A. H. (2012). Overweight and school performance among primary school children: The PIAMA birth cohort study. Obesity, 20(3), $590-596$.

Wang, F., \& Veugelers, P. J. (2008). Self-esteem and cognitive development in the era of the childhood obesity epidemic. Obesity Reviews, 9(6), 615-623.

Wang, G., \& Dietz, W. H. (2002). Economic burden of obesity in youths aged 6 to 17 years: 1979-1999. Pediatrics, 109(5), E81-81.

Wang, L. Y., Yang, Q., Lowry, R., \& Wechsler, H. (2003). Economic analysis of a school-based obesity prevention program. Obesity Research, 11(11), 1313-1324. 
Wang, Y., Beydoun, M. A., Liang, L., Caballero, B., \& Kumanyika, S. K. (2008). Will all Americans become overweight or obese? Estimating the progression and cost of the US obesity epidemic. Obesity, 16(10), 2323-2330.

West, F., Sanders, M. R., Cleghorn, G. J., \& Davies, P. S. W. (2010). Randomised clinical trial of a family-based lifestyle intervention for childhood obesity involving parents as the exclusive agents of change. Behav Res Ther, 48(12), 1170-1179. doi: DOI 10.1016/j.brat.2010.08.008

Wieting, J. M. (2008). Cause and effect in childhood obesity: Solutions for a national epidemic. J Am Osteopath Assoc, 108(10), 545-552.

Williams, C. L., Hayman, L. L., Daniels, S. R., Robinson, T. N., Steinberger, J., Paridon, S. M., \& Bazzarre, T. (2002). Cardiovascular health in childhood: A statement for health professionals from the Committee on Atherosclerosis, Hypertension, and Obesity in the Young (AHOY) of the Council on Cardiovascular Disease in the Young, American Heart Association. Circulation, 106(1), 143-160.

Williams, J. E. (2011). Child obesity in context: Ecology of family and community. International Journal of Exercise Science, 4(2), 86-92. 


\section{APPENDICES}

\section{APPENDIX A}

\section{Pedometer Log Sheet for $k-5^{\text {th }}$ Grade Students}

\section{Student's}

name

\section{Student's}

grade

\section{Student's classroom}

teacher

\section{Student's}

school

Time and Date the pedometer was first worn by student

*Directions: Fill out the box below each night before you go to bed.

Do not wear the pedometer in the shower, bath, or while swimming.

\begin{tabular}{|c|c|c|}
\hline & Number of steps taken that day & $\begin{array}{c}\text { Time and date this number was } \\
\text { recorded from pedometer }\end{array}$ \\
\hline Day 1 & & \\
\hline Day 2 & & \\
\hline Day 3 & & \\
\hline
\end{tabular}

*Parents and Guardians: 
Student should attach the pedometer to the waistband of his or her clothing as he or she gets dressed at the beginning of Day 1. This will ensure that the pedometer captures steps for as close to a full day as possible, every day.

Also, check every morning that the pedometer has been reset to zero steps.

Each night, the pedometer should be removed before bedtime.

At that point, the student should record the number of steps he or she took that day. Once that day's steps have been written down on this sheet, the pedometer should be reset to zero.

Place the pedometer in a safe place where the student will remember to put it on the next day.

After Day 4, student should return the pedometer to the school's classroom teacher.

If the student is sick during one or more days that he or she is supposed to be wearing the pedometer, note that in the middle of the column of the above table.

Steps do not need to be recorded if the student is sick. 


\section{APPENDIX B}

Nutrition Survey for K-5 ${ }^{\text {th }}$ Grade Students

\section{Student's}

name

\section{Student's}

grade

\section{Student's classroom}

teacher

\section{Student's}

school

\section{Time and}

Date

\section{Directions: For each question, circle only 1 answer.}

1. Yesterday, did you eat fruit? Fruits are all fresh, frozen, canned, or dried fruits.

Do not count fruit juice.

$0 \quad$ No, I didn't eat any fruit yesterday.

$1 \quad$ Yes, I ate fruit 1 time yesterday.

$2 \quad$ Yes, I ate fruit 2 times yesterday.

$3 \quad$ Yes, I ate fruit 3 times yesterday.

$4 \quad$ Yes, I ate fruit 4 times yesterday.

$5 \quad$ Yes, I ate fruit 5 or more times yesterday.

2. Yesterday, did you eat any starchy vegetables like potatoes, corn, or peas?

Do not count French fries or chips.

$0 \quad$ No, I didn't eat any of the foods listed above yesterday.

1 Yes, I ate one of these foods 1 time yesterday.

2 Yes, I ate one of these foods 2 times yesterday.

3 Yes, I ate one of these foods 3 or more times yesterday. 
3. Yesterday, did you eat any orange vegetables like carrots, squash, or sweet potatoes?

$0 \quad$ No, I didn't eat any orange vegetables yesterday.

$1 \quad$ Yes, I ate orange vegetables 1 time yesterday.

2 Yes, I ate orange vegetables 2 times yesterday.

3 Yes, I ate orange vegetables 3 times yesterday.

$4 \quad$ Yes, I ate orange vegetables 4 times yesterday.

$5 \quad$ Yes, I ate orange vegetables 5 or more times yesterday.

4. Yesterday, did you eat a salad made with lettuce, or any green vegetables like spinach, green beans, broccoli, or other greens?

$0 \quad$ No, I didn't eat any salad or green vegetables yesterday.

1 Yes, I ate salad or green vegetables 1 time yesterday.

2 Yes, I ate salad or green vegetables 2 times yesterday.

3 Yes, I ate salad or green vegetables 3 times yesterday.

4 Yes, I ate salad or green vegetables 4 times yesterday.

5 Yes, I ate salad or green vegetables 5 or more times yesterday.

5. Yesterday, did you eat any other vegetables like peppers, tomatoes, zucchini, asparagus, cabbage, cauliflower, cucumbers, mushrooms, eggplant, celery, or artichokes?

$0 \quad$ No, I didn't eat any of the foods listed above yesterday.

1 Yes, I ate one of these foods 1 time yesterday.

2 Yes, I ate one of these foods 2 times yesterday.

$3 \quad$ Yes, I ate one of these foods 3 times yesterday.

4 Yes, I ate one of these foods 4 times yesterday.

$5 \quad$ Yes, I ate one of these foods 5 or more times yesterday. 


\title{
CURRICULUM VITAE
}

\author{
Jiying Ling, BSN, Ph.D. Candidate \\ 210 Bontressa Drive Apt. \#1 Louisville Kentucky 40206 \\ Phone: (502) 852-6946 (Office) Email: j0ling02@ louisville.edu
}

\section{EDUCATION}

Ph.D., Nursing

Expected December 2013

University of Louisville

Research Area: Childhood Obesity Intervention (Healthy Behavior Promotion)

Dissertation: Psychosocial and environmental determinants of physical activity in elementary school children: Implications for potential interventions to reduce childhood obesity

GPA: $3.97 / 4.0$

M.S., Biostatistics

May 2013

University of Louisville

Thesis: Preliminary assessment of a school-based healthy lifestyle program among rural children GPA: $4.0 / 4.0$

M.S., Nursing (not completed)

Shandong University, China

September 2008-June 2009

Concentration: Critical Care Nursing

Credits Earned: 25.5

GPA: $89.7 / 100$

B.S., Nursing

July 2008

Shandong University, China

GPA: $85.1 / 100$

\section{APPOINTMENT}

Graduate Research Assistant

2009-Present

School of Nursing, University of Louisville

Statistics Tutor

School of Nursing, University of Louisville

Graduate Research Assistant for Dr. Celeste Shawler

School of Nursing, University of Louisville
May-August 2010 
School of Nursing, Shandong University, China

\section{GRANTS}

Psychosocial and environmental determinants of physical activity in

elementary school children: Implications for potential interventions to reduce childhood obesity. Jiying Ling (PI)

Sigma Theta Tau International-Iota Zeta Chapter Research \& Scholarship Award (\$500), Graduate Student Council Research Fund (\$300)

Exploring the needs and attitudes about pre-hospital care

among college students. Jiying Ling (PI)

Shandong University Innovative Research Grant, ¥ 1,200

\section{JOURNAL PEER REVIEWER}

Nursing: Research and Reviews

2012-Present

Open Access Medical Statistics

2012-Present

\section{PUBLICATIONS}

King, K., Ling, J., Ridner, L., Jacks, D., Newton, K., \& Topp, R. (2013). Fit into College II: Physical activity and nutrition behavior effectiveness and programming recommendations. Recreational Sports Journal, 37(1), 29-41.

Ling, J., King, K., Speck, B., Wu, D., \& Kim, S. (2013). Preliminary assessment of a school-based healthy lifestyle program among rural children: Project BALANCE. Annals of Behavioral Medicine, 45(Abstract Supplement), s28.

Wang, X., \& Ling, J. (2012). Multiple valued logic approach for matching patient records in multiple databases. Journal of Biomedical Informatics, 45, 224-230. doi:10.1016/j.jbi.2011.10.009

Ling, J., Liu, J., Liu, C., Zou, F., \& Wang, K. (2009). Knowledge and attitudes about pre-hospital care among college students. Journal of Nursing Science, 24(2), 7981.

\section{PRESENTATIONS}

\section{National}

Ling, J., King, K., Speck, B., Wu, D., \& Kim, S. Preliminary assessment of a schoolbased healthy lifestyle program among rural children: Project BALANCE. The $34^{\text {th }}$ Annual Meeting \& Scientific Sessions of the Society of Behavioral Medicine, San Francisco, CA. March 20-23, 2013. 
Ling, J., Jacks, D. E., King, K., Ridner, S. L., Conte, K., \& Topp, R. Effects of a 10week fitness program on fitness and perceptions of nutrition and physical activity among overweight and normal weight college students. NINR's $25^{\text {th }}$ Anniversary Concluding Scientific Symposium, Washington, DC. October 13, 2011.

\section{$\underline{\text { Regional }}$}

Speck, J. B., \& Ling, J. Barriers to regular physical activity in rural and urban lowincome women (Poster Discussion Presentation). Midwest Nursing Research Society 37th Annual Conference, Chicago, IL. March 7-10, 2013.

Ling, J., King, K., Speck, B., Wu, D., \& Kim, S. Preliminary assessment of a schoolbased healthy lifestyle program among rural children (Top Student Poster Discussion Presentation). Southern Nursing Research Society $27^{\text {th }}$ Annual Conference, Little Rock, Arkansas. February 27- March 2, 2013.

Jackson, B. M., Lehna, C., Alaradi, M., \& Ling, J. Differences in children's home safety practices between families living in rural and urban areas. Southern Nursing Research Society 27th Annual Conference, Little Rock, Arkansas. February 27March 2, 2013.

Ling, J., \& Speck, J. B. Perceived barriers to physical activity in rural and urban lowincome women. Midwest Nursing Research Society $36^{\text {th }}$ Annual Conference, Dearborn, Michigan. April 12-15, 2012.

Ling, J., Alaradi, M., Jackson, B., \& Lehna, C. What baccalaureate registered nursing students found out from a home safety assignment. Southern Nursing Research Society $26^{\text {th }}$ Annual Conference, New Orleans, Louisiana. February 22-25, 2012.

Speck, J. B., \& Ling, J. Descriptive study of participants attending a health fair in a low income urban neighborhood. Midwest Nursing Research Society $35^{\text {th }}$ Annual Conference, Columbus, Ohio. March 24-27, 2011.

Ling, J., \& Shawler, C. Body mass index is associated with health related quality of life among older mother-adult daughter dyad. Southern Nursing Research Society $25^{\text {th }}$ Annual Conference, Jacksonville, Florida. February 16-19, 2011.

\section{HONORS AND AWARDS}

PhD Program Travel Funds (\$300)

School of Nursing, University of Louisville

Graduate Student Council (GSC) Travel Funds (\$350)

University of Louisville

Ruth Craddock Research Fund (\$500)

2012

School of Nursing, University of Louisville

Who's Who among Students in American Universities \& Colleges

2012 
in recognition of outstanding merit and accomplishment as a student at University of Louisville

Outstanding Adult Learner Award for Graduate Student

Kentuckiana Metroversity

Ruth Craddock Research Fund (\$500)

School of Nursing, University of Louisville

Government-Sponsored Graduate Student

Shandong University, China

"What can we do after earthquake" contest, Commemoration Prize

Shandong University, China

Outstanding Volunteer

2008

Shandong Province, China

"May 4 th" Academic Paper Competition, Second Place

Shandong University, China

Tenth "Challenge Cup", Third Place

2007

Shandong University, China

Outstanding Undergraduate Student

Shandong University, China

University Scholarship, Second Place

Shandong University, China

\section{PROFESSIONAL MEMBERSHIPS}

Society of Behavioral Medicine

2013-Present

Honor Society of Nursing Sigma Theta Tau International

2011-Present

Southern Nursing Research Society

2011-Present

Abstract Reviewer for SNRS 27 $7^{\text {th }}$ Annual Conference, 2013

Midwest Nursing Research Society

2011-Present

NATIONAL BOARD CERTIFICATE AND STATE RN LICENSURE

California ( $\mathrm{RN}$, in process), USA

Shandong (RN), China

License No: 201037002002

Certificate of General Management Proficiency

China Employment Training Technical Instruction Center

Certificate No: 20071031501400093
Expected August 2013

March 2010-March 2015

July 2007-Present 
First Aider Certificate

2005- Present

Red Cross Society of China

Certificate No: 20050096

\section{CLINICAL PRACTICE}

First Affiliated Hospital of Dalian Medical University, China

2007-2008

\section{COMMITTEES AND SERVICES}

Wellington Elementary School, School Wellness Policy, Evaluator

2012

Atkinson Elementary, Summer Booth for Students with Learning Disabilities, Tutor 2012

Indiana/Kentucky Tornado Relief, Volunteer 2012

University of Louisville, Department of Mathematics, Tutor

2011

University of Louisville, Association of Graduate Nursing Students, Treasurer 2009-2010

China, Sichuan Earthquake Relief, Volunteer

May 2008 